\title{
Independent Technical Review of the Department of Energy Office of Legacy Management UMTRCA Groundwater Program
}

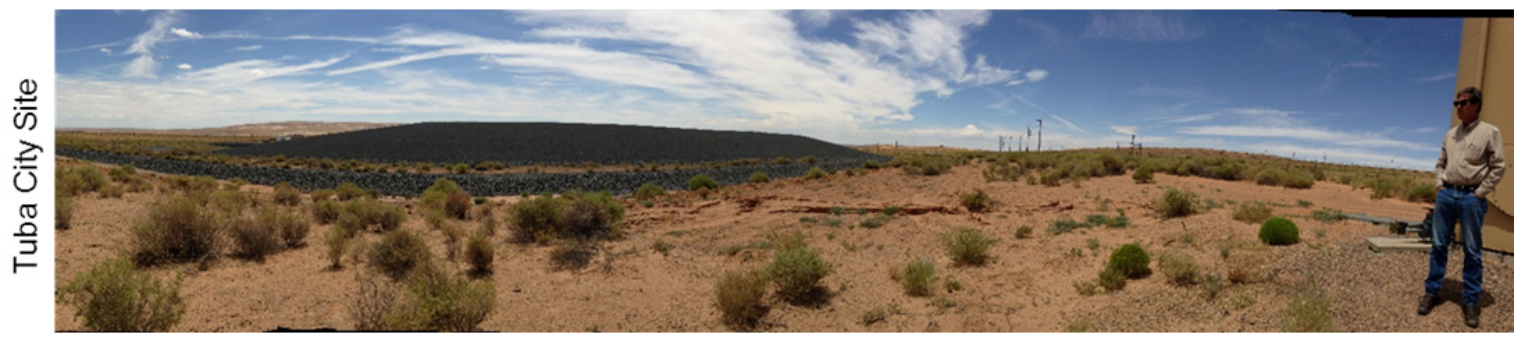

September 2013

Prepared for: The U.S. Department of Energy (DOE) Office of Legacy Management (LM) Prepared by: The DOE EM Center for Sustainable Groundwater and Soil Solutions, Savannah River National Laboratory, Aiken SC

Technical content and coordination for this effort was provided by the Savannah River National Laboratory in conjunction with Contract No. DE-AC09-08SR22470 with the U.S. Department of Energy. 

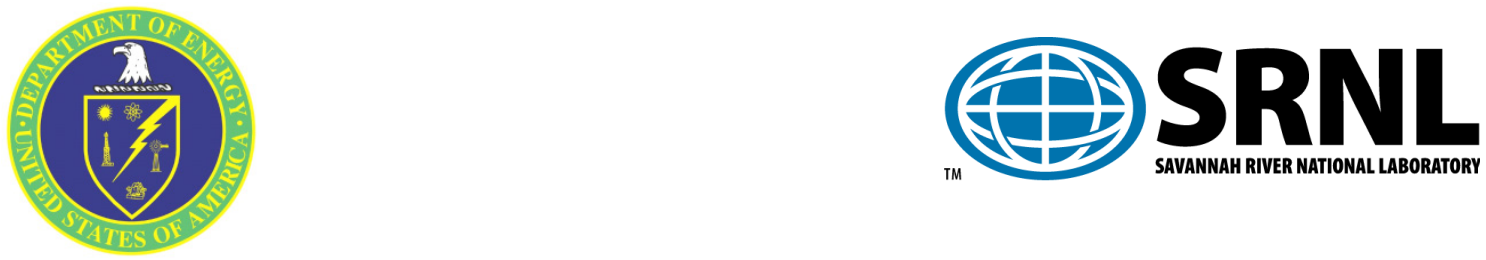

Cover Panoramic Photo: Mark Kautsky, DOE-LM Program Manager, surveys the current conditions at Tuba City - a former uranium processing and tailings disposal site with active groundwater remediation underway

\section{DISCLAIMER}

This work was prepared under an agreement with and funded by the U.S. Government. While the authors have taken care in the preparation of this report, neither the U. S. Government or its employees, nor any of its contractors, subcontractors or their employees, makes any express or implied: 1. warranty or assumes any legal liability for the accuracy, completeness, or for the use or results of such use of any information, product, or process disclosed; or 2. representation that such use or results of such use would not infringe privately owned rights; or 3. endorsement or recommendation of any specifically identified commercial product, process, or service. Any views and opinions of authors expressed in this work do not necessarily state or reflect those of the United States Government, or its contractors, or subcontractors.

\section{Printed in the United States of America}

Prepared For

U.S. Department of Energy 


\title{
Independent Technical Review of the Department of Energy Office of Legacy Management UMTRCA Groundwater Program
}

\author{
Authors: \\ Brian B. Looney, Savannah River National Laboratory \\ Miles E. Denham, Savannah River National Laboratory \\ Carol A. Eddy-Dilek, Savannah River National Laboratory \\ Margaret R. Millings, Savannah River National Laboratory
}

Prepared for

U.S. Department of Energy Office of Legacy Management

September 2013

Technical content and coordination for this effort was provided by the Savannah River National Laboratory in conjunction with Contract No. DE-AC09-08SR22470 with the U.S. Department of Energy. 


\section{Table of Contents}

\section{Executive Summary}

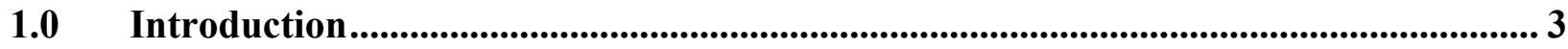

2.0 Technical Frameworks and Overarching Recommendations ...................................... 4

2.1 Spatial/Temporal Conceptual Framework for Uranium Tailings Disposal Sites

2.2 Hydrologic Conceptual Framework for Uranium Tailings Disposal Sites

2.3 Geochemical Framework for Uranium Tailings Disposal Sites

2.4 Natural Attenuation Mechanisms for Uranium and Nitrate

2.5 Active Remediation Strategies for Uranium

2.6 Monitoring

3.0 Site Specific Observations and Recommendations - Tuba City.

3.1 Approach

3.2 Tuba City: Hydrologic Conceptual Framework

3.3 Tuba City: Spatial/Temporal Frameworks

3.4 Tuba City: Geochemical Framework

3.5 Application of Key Tuba City Frameworks: Legacy Management Challenges and Opportunities

4.0 Site Specific Observations and Recommendations - Gunnison ...............................5 51

$5.0 \quad$ Recommendations and Conclusions ............................................................................5 55

Appendix A Statement of Work

Appendix B Technical Team Biographies 


\section{List of Figures}

Figure 1. Simplified conceptualization of facility impacts on the surrounding environment and technology matching principles..... 6

Figure 2. Stability of U(VI)-silicate minerals relative to schoepite; in equilibrium with calcite, quartz, atmospheric PO2, and PCO2=0.01 atmospheres.....9

Figure 3. Stability of U(IV) phases with equal activity line for the ferrous-ferric iron couple ....10

Figure 4: Tuba City: former processing facility and disposal cell showing the current configuration and regional topography.....14

Figure 5. Example nested flow lines for a site with local and regional water sources and sinks

Figure 6. Hydrogeologic cross section with key flow lines depicted; brown lines approximate the path of contaminated water......15

Figure 7. Hydrogeologic cross section with key flow lines depicted; brown lines approximate the path of contaminated water.....16

Figure 8. Key geochemical processes associated with non-pedogenic mineral accumulations in arid and semi-arid settings - a) general concept and b) annotated to highlight probable mineral accumulation zones for Tuba City......17

Figure 9. Minerals precipitated during simulated degassing(a) and evaporation(b) of background and contaminated groundwater at Tuba City.....22

Figure 10. Simplified temporal framework for the stages at the former Tuba City Processing Site......24

Figure 11. Diagrams showing possible scenario for infiltration of sulfuric acid process fluids into aquifer with natural calcite (a) followed by infiltration of sodium carbonate fluids (b).....28

Figure 12. Activity-activity diagram of $\mathrm{Ca}^{+2}$ vs. $\mathrm{SO}_{4}{ }^{-2}$ showing the composition of Tuba City groundwater relative to the stability fields of gypsum and calcite; Horizon A wells (blue triangles), Horizon B wells (blue stars), background wells (green circles); red dotted line shows stability fields under background conditions......28

Figure 13. Tuba City groundwater compositions (DOE, 2012) relative to the stability fields of soddyite and carnotite; Horizon A wells (blue triangles), Horizon B wells (blue stars), background wells (green circles); red dotted line shows stability fields under background conditions......30

Figure 14. Example of commercially available reverse osmosis system - approximate size scale needed for Tuba City groundwater treatment....34 
Figure 15. Example of commercially available spray evaporation system......35

Figure 16. Hypothetical behavior of depth profiles that would help confirm and quantify the evaporative discharge boundary...... 39

Figure 17A. Terrestrial gamma exposure map (uR/hr) based on North America NURE Dataset.....44

Figure 17B Terrestrial gamma exposure map ( $\mathrm{uR} / \mathrm{hr}$ ) from NURE dataset for New Mexico Area.....44

Figure 17C Terrestrial gamma exposure map ( $\mathrm{uR} / \mathrm{hr}$ ) from NURE dataset for the area around the Tuba City Mill Site.....45

Figure 18. High resolution terrestrial gamma exposure map $(\mathrm{uR} / \mathrm{hr})$ in the vicinity of the Tuba City Mill Site.....46

Figure 19. High resolution ${ }^{214} \mathrm{Bi}$ exposure map (uR/hr) in the vicinity of the Tuba City Mill Site.....47

Figure 20. Predominant wind direction and summary of transport vectors in the vicinity of the Tuba City Mill Site.....48

Figure 21. Summary of the process to transition the Tuba City Site to beneficial reuse.....50

Figure 22. Gunnison Processing Site: Former uranium milling and processing area near Gunnison Colorado.....51

Figure 23. Gunnison Disposal Site: Cell containing stabilized tailings and contaminated materials removed from the Gunnison Processing Site.....51

Figure 24. Example Concept - Passive Barometric pumping for control of vapor moisture in a hypothetical tailings cell..... 54

\section{List of Tables}

Table 1. Methods for Characterization of the Evaporative Boundary Zone.....40 


\section{Acronyms and Abbreviations}

\begin{tabular}{|c|c|}
\hline AZ & Arizona \\
\hline CDPHE & Colorado Department of Public Health and Environment \\
\hline $\mathrm{CO}$ & Colorado \\
\hline $\mathrm{cu}$ & Cubic \\
\hline $\mathrm{C}_{\mathrm{w}}$ & contaminant concentration in groundwater \\
\hline DOE & U.S. Department of Energy \\
\hline EM & DOE Office of Environmental Management \\
\hline EM-12 & DOE Office of Soil and Groundwater Remediation \\
\hline EPA & U.S. Environmental Protection Agency \\
\hline ESTCP & DoD Environmental Security Technology Certification Program \\
\hline $\mathrm{ft}$ & foot (or feet) \\
\hline FY & fiscal year \\
\hline gal, gpm, gpd & gallon, gallons per day, gallons per minute \\
\hline $\mathrm{K}_{\mathrm{d}}$ & partition coefficient of a contaminant between soil and groundwater \\
\hline $\mathrm{Kg}$ & Kilogram \\
\hline $\mathrm{km}$ & Kilometer \\
\hline LM & DOE Office of Legacy Management \\
\hline $\mathrm{L}, \mathrm{m}$ & liter, meter \\
\hline MCL & maximum contaminant level \\
\hline MNA & monitored natural attenuation \\
\hline msl & mean sea level \\
\hline $\mathrm{mSv}, \mathrm{MSv} / \mathrm{yr}$ & milliSievert, milliSievert per year (hour, etc.) \\
\hline O\&M & operation and maintenance \\
\hline $\mathrm{p} \& \mathrm{t}$ & pump and treat \\
\hline REM & Dose unit - Radiation Equivalent Man \\
\hline SRS & Savannah River Site \\
\hline SRNL & Savannah River National Laboratory \\
\hline $\mathrm{Sv}$ & Dose unit -- Sieverts \\
\hline TAT & Technical Assistance Team \\
\hline $\begin{array}{l}\text { UMTRCA } \\
\text { wt } \%\end{array}$ & $\begin{array}{l}\text { Uranium Mine Tailings Radiation Control Act } \\
\text { percent by weight }\end{array}$ \\
\hline yds & Yards \\
\hline$\mu \mathrm{g} / \mathrm{kg}, \mu \mathrm{g} / \mathrm{L}$ & micrograms per kilogram, micrograms per liter, etc. \\
\hline$\mu \mathrm{g} / \mathrm{L}$ & micrograms per liter \\
\hline$\mu \mathrm{R} / \mathrm{hr}$ & microRoentgens per hour \\
\hline
\end{tabular}




\section{Executive Summary}

Work performed to date by the Department of Energy (DOE) Legacy Management (LM) team has yielded high-quality data and a sound general conceptualization of the UMTRCA sites. The Technical Assistance Team (TAT) visited two UMTRCA sites, Tuba City, AZ, and Gunnison, $\mathrm{CO}$, and had discussions with contractor and LM personnel working on these sites. The visits, discussions and review of the extensive documentation from these sites provided the TAT with in depth examples representative of many of the other sites in the UMTRCA program. Tuba City is an example of an active remediation site with an on-site tailings disposal cell. Gunnison is a natural flushing site with an off-site tailings disposal cell.

In reviewing the available data, the TAT developed an overarching set of frameworks that potentially dovetail with existing conceptual models/approaches for UMTRCA sites and might provide areas of opportunity for the DOE LM program. The frameworks provide a consistent way of organizing and interpreting complex data in a manner that supports environmental decision making. The individual frameworks include:

1) Spatial Framework - places plume data within the spatial context of the sites from source to plume fringe; different locations within the spatial framework require different approaches to characterization, remediation and monitoring

2) Temporal Framework - relates plume data to events in the history of the site from initiation of the processes that caused contamination, through remedial action

3) Hydrological Framework - relates plume data to the physical forces driving plume movement including boundary conditions such as streams and, in arid climates, the capillary fringe

4) Geochemical Framework - describes the interactions of plume constituents with aquifer materials and uncontaminated groundwater, as well as other geochemical process affecting contaminant migration

When site information is organized into these frameworks the interrelationships become more apparent facilitating holistic conceptual model development. The Tuba City and Gunnison sites provide examples of how a framework approach applies to site conceptual models.

Tuba City shows complex interrelations between frameworks reflecting the complicated history of the site, the location of the site relative to important geomorphic features, the influence of an arid climate, and geochemical interactions that have impact contaminant migration and hydrologic properties. Application of the hydrologic, and geochemical frameworks at Tuba City suggest that, in this arid setting, shallow contaminated groundwater is transferred into the vadose zone and atmosphere via evaporation, transpiration and seepage and the water flowing to Moenkopi Wash is from the deep uncontaminated portion of the aquifer. Further, in the areas of groundwater evaporation, transpiration or seepage, dissolved constituents in the groundwater are projected to precipitate and accumulate as common minerals. Primary accumulations will be in the deep vadose zone (near the capillary fringe), around the roots of phreatophyte plants, and near surface water seeps. A clear and robust scientific conceptualization that site-specific conditions limit the size of the groundwater plume and naturally attenuate and detoxify the latent 
environmental groundwater impacts of the former Tuba City processing operations is potentially transformational.

The TAT identified a number of Tuba City challenges associated with the operation of the groundwater pump and treat system, both in the above ground water treatment process and in the subsurface extraction well network. The net result of these challenges is a costly and relatively "ineffective" active treatment system that may provide levels of environmental protection that are similar to natural attenuation. Based on the evaluation, we developed a range of specific technical-policy-engineering recommendations for DOE LM to consider. Importantly, the TAT urged a focused characterization of the natural attenuation processes occurring along the flow path and incorporation of the findings into future planning and decision making. If these attenuation processes are effectively limiting the extent and impact of the groundwater plume, then the pump and treat could be safely discontinued and the site transitioned to an alternativebeneficial end state.

As with Tuba City, the Gunnison Sites have been well managed by DOE-LM. For the former Gunnison Processing Site, the TAT applied a supplemental hydrologic framework that suggested that increased focus on monitoring, and understanding the role of, hydrologic boundary conditions in the nearby streams and mining operations would be prudent. The Gunnison Disposal Site appears to be well sited and protective of the groundwater.

Applying, confirming and accounting for the key features of the various applied science frameworks is a powerful approach that would supplement the efforts of DOE LM to protect human health and the environment at sites with groundwater contamination. The TAT determined that this supplemental approach may be critical to developing an effective and efficient long term strategy for Tuba City. Further, our evaluation of the LM case study sites highlights the potential importance of the frameworks for almost all LM sites, particularly those with complex history or geochemistry and/or those in arid settings where the impacts of small changes in hydrologic boundary conditions are relatively important on an absolute basis.

The TAT found the programmatic actions taken by DOE-LM and their contractors to be of high quality and protective of human health and the environment. LM has a strong administrative, management and technical staff and contractors that has demonstrated skill in managing their complex portfolio of sites and that is fully capable of incorporating our recommendations throughout the program. 


\subsection{Introduction}

In 1978, the U.S. Congress established a uranium mill remedial action program (Title I of Uranium Mill Tailing Radiation Control Act) to provide funding for remediation of selected inactive uranium ore-processing sites. The program is administered by the DOE Office of Legacy Management. At some of the selected former processing sites, the residual radioactive material was sequestered in place; and, at other sites, the residual radioactive material was moved from the processing sites to offsite disposal locations. At the processing sites where the groundwater was contaminated, groundwater compliance action plans with compliance strategies have been or are being developed by DOE. The remedial strategies that have been implemented at these sites fall into two general categories, specifically, natural flushing which must be completed within 100 years or active remediation.

For over two decades, the Savannah River National Laboratory (SRNL) has managed a Technical Assistance program focused on providing technical support to the larger DOE complex. The Department of Energy Office of Legacy Management requested that SRNL provide independent technical experts to evaluate the effectiveness of ongoing remediation and monitoring activities at UMTRCA Title I sites with contaminated groundwater. Two representative UMTRCA sites were chosen for review, specifically Tuba City, AZ, an example of active remedial site, and Gunnison, $\mathrm{CO}$ as an example of a natural flushing site.

The selected group of technical experts visited the Tuba City and Gunnison site processing and storage facilities during late July and early August 2013. LM and contractor personnel briefed the team during the Tuba City visit; LM, contractor and Colorado Department of Public Health and the Environment (CDPHE) representatives participated on the visit to the Gunnison processing and disposal cell. On subsequent days, the team reviewed baseline data and reports, discussed technical issues with LM and contractor personnel, in order to develop a set of overarching recommendations for the groundwater monitoring program as well as specific recommendations for both Tuba City and Gunnison sites.

In general, the review team found the programmatic actions taken by DOE-LM and their contractors to be protective of human health and the environment. Specifically, the team noted that DOE-LM has developed an organized and consistent, "formalized," approach to decision making, cleanup and monitoring. The documentation provided indicates a quality assurance (QA) plan is in place to handle sampling and analysis validation. Standard statistical interpretation of monitoring is being performed and explicit decision rules are generally stated in the groundwater compliance action plan (GCAP) to support longer term LM assessment of compliance. The review team particularly commends DOE LM for their efforts to make site documents and data easily and publically available for all of their sites through the web in a consistent and organized manner (at www.lm.doe.gov). Despite the general and specific high level of performance of the DOE-LM organization, the review team identified a number of areas in which innovative technical and scientific approaches have the potential to significantly improve the LM program. In general, these involve development and application of applied science frameworks to improve site conceptual models, reduce costs, improve remedy selection/performance, and develop better strategies for achieving compliance. 


\subsection{Technical Frameworks and Overarching Recommendations}

Development of technical frameworks is a key strategy to apply basic science to an applied field problem. When directed toward understanding complex real-world environmental remediation challenges, frameworks are tools that support practical identification and incorporation of the key-controlling scientific processes and principles. Frameworks can also be used to minimize technical risks, encourage efficiency and effectiveness, and provide the basis for innovative and creative solutions. The following paragraphs summarize the approach for generating spatial, temporal, and various conditional site-specific frameworks. As will be documented in the selected case studies (Tuba City Processing/Disposal Site and the Gunnison Processing and Disposal Sites), these general framework approaches are applicable to almost all remediation sites, and the various frameworks can be used alone, or in combination, to provide valuable support in managing legacy contamination areas, especially, the other UMTRCA sites.

\subsection{Spatial/Temporal Conceptual Site Model for Uranium Tailings Disposal Sites}

\section{$\underline{\text { Spatial Conceptual Framework }}$}

Efficient and effective environmental cleanup requires matching the character of remediation and stabilization methods to the nature of the target zone of contamination as the nature of the target zone evolves through the life of the remedial project. Figure 1 shows the different areas of a generalized contaminant plume, i.e., the disturbed zone, the impact zone, and the transitional zone, and describes the general characteristics of each zone. Thus, physical and chemical methods (e.g., trapping, immobilization, destruction, or isolation) that directly address the source contaminants are often appropriate for the disturbed zone during the remedial process. A variety of methods that include both active treatments (e.g., pump and treat or active bioremediation) and enhanced attenuation technologies (e.g., geochemical manipulation or reactive barriers) are often suitable for the primary contamination zone or impact zone. Various strategies based on natural attenuation processes may be applicable to the primary contamination zone and these methods are typically applied for the transition or baseline portions of the plume. This spatial conceptual framework, based on matching technology attributes to site-specific conditions and needs, has proven to be effective in supporting environmental management decisions. Key factors in selecting rational and optimal remedy(ies) include implementability, expected performance, uncertainties/risks, and costs for actions as they apply to the various target zones. In addition to the traditional factors, emphasis is increasingly placed on sustainability and metrics for evaluating remedial actions and balancing benefits against the associated environmental burdens and collateral damages. 


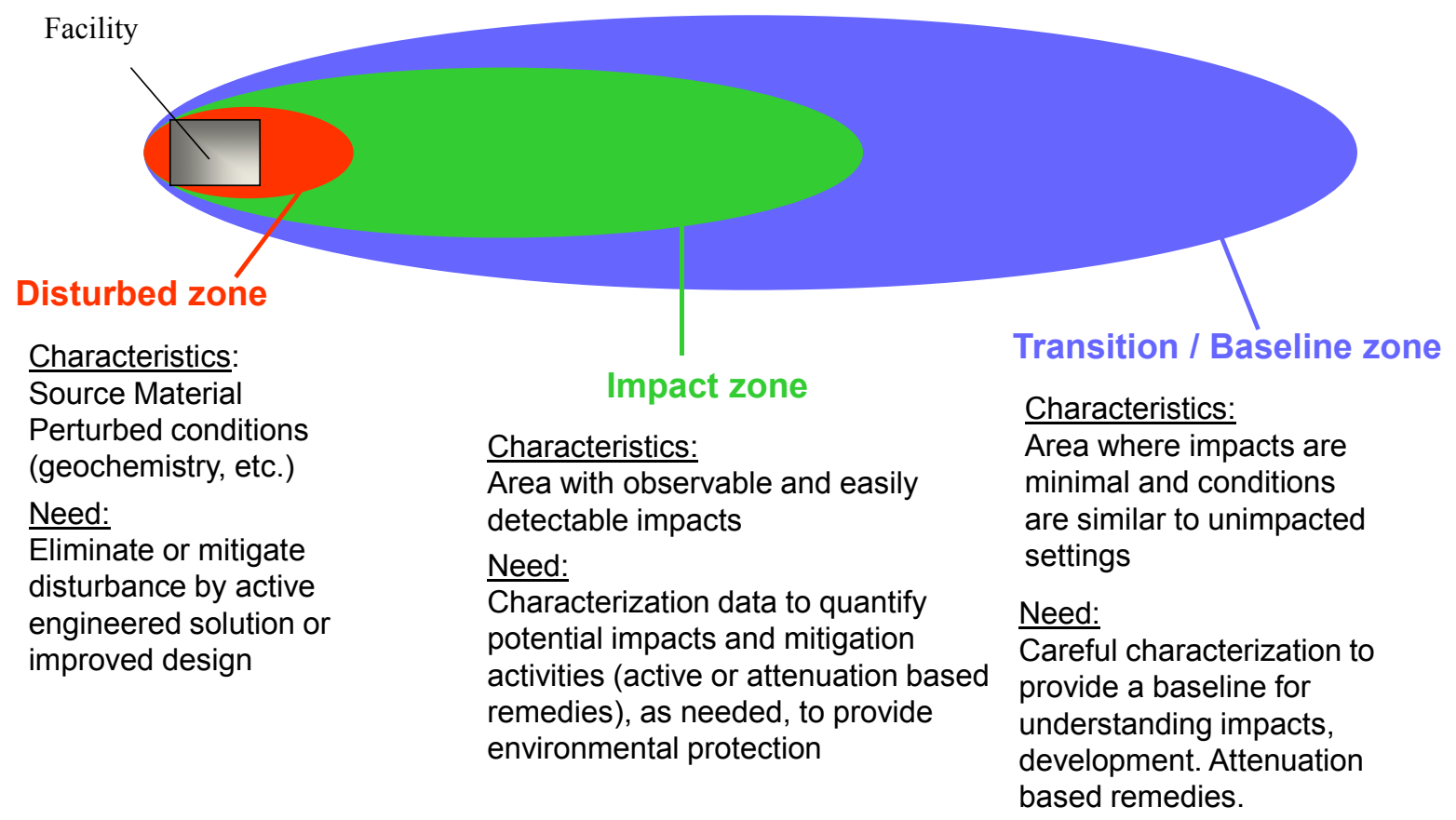

Figure 1. Simplified conceptualization of facility impacts on the surrounding environment and technology matching principles. Colored ovals show generalized zones of the plume.

\section{$\underline{\text { Temporal Conceptual Framework }}$}

It is important to recognize that a contaminant plume transitions through a series of stages during which key hydrologic and geochemical parameters can dramatically evolve and change. Thus, a temporal conceptual framework is also important. An effective approach for a specific contaminated site may involve implementation of a sequence of technologies.

The first stage at a contaminated site is characterized by the hydrologic conditions that are present during disposal operations and prior to initiation of remedial activities. This period is characterized by the primary disposal actions and potential release of contaminants and often includes geochemical and hydrologic perturbations (e.g., altered/extreme $\mathrm{pH}$ or release of large amounts of water).

In the second stage, after active remedial activities are initiated, conditions at the site change. The hydrology of the site may be altered, for example, water associated with waste disposal may be discontinued, but water may be applied as part of the construction operations. Waste may be physically or chemically immobilized in place or excavated and removed from the site. Hydrologic boundary conditions are often modified by addition of amounts of water for dust suppression, installation of physical barriers, or installation of trenches/clean water discharge points. The dynamic between the source material and hydrologic system is also often significantly perturbed, for example, often the source material is isolated from interaction with the site groundwater. The geochemistry of the site, both source and plume, can be fundamentally changed by the installation of physical barriers and/or chemical changes to the subsurface by 
groundwater treatment systems or the addition of amendments. Even after remedial activities have been completed, these actions continue to influence the site until the perturbations reequilibrate. For example, water that is present in residual waste and water applied during active remediation will slowly dissipate and the site will equilibrate and transition to the third stage $-\mathrm{a}$ groundwater treatment and/or flushing stage. During the transition, mass discharge of contamination from the source into the groundwater decreases. Perturbations introduced during this phase are often long-lived, commonly persisting for over a decade. Many of the LM UMTRCA sites are currently exhibiting characteristics that are typical of these types of transitions.

Once the source mass flux and hydrology of the site have equilibrated, the behavior of the residual contaminant plume is modulated by long term site conditions. During this third stage, groundwater concentration trends (e.g., from flushing) stabilize and more definitive assessments of remediation timeframes can be developed. Use of groundwater modeling and statistical trend analysis (e.g., Mann-Kendall tests) may be appropriate during this third stage. The ultimate goal of these analyses is to understand the dynamics of how the plume will wash through a system, and to assess the mass balance in the groundwater system. When the mass release rate (discharge or flux) from the source is greater than the natural attenuation occurring in the footprint of the plume, the plume will expand. When the plume reaches a size such that the attenuation occurring within the plume footprint is equal to (or greater than) the mass release rate from the source, then the plume will stabilize (or shrink). Depletion of the source or implementation of remediation technologies, such as source treatment, can alter conditions during specific time period(s), changing the total mass entering the groundwater plume, and the structure of the resulting plume. Plume status is often combined with local issues (e.g., crossing property boundaries or impacting a water supply) and the expected performance characteristics of a selected remediation technology in order to generate appropriate metrics to monitor and/or track progress at a particular site.

Use of the mass balance approach to support remedial decision-making is powerful because it allows site representatives to make technology decisions in a succinct and intuitive manner, and it provides the opportunity to develop simple tools to predict the temporal impacts of alternative remedial actions (ITRC, 2010). Moreover, a mass balance approach can be implemented based on relatively few parameters. Several of these parameters (e.g., groundwater flow velocity and direction and contaminant discharge from the source) can be estimated from standard monitoring data. Other key parameters, such as attenuation rates in plumes, can be estimated based on mechanism-specific studies (e.g., laboratory microcosms); correlations of site characterization data to rates (e.g., relating reactive mineral content and surface area to contaminant transformation); or evaluation of field scale plume structure (Newell et al., 2002). Identification, characterization, and quantification of the processes that control and attenuate contaminants are crucial to effective environmental management decisions for large dilute contaminant plumes.

\subsection{Hydrologic Conceptual Framework for Uranium Tailings Disposal Sites}

In arid environments typical of most of the UMTRCA facilities, hydrologic boundary conditions are a major influence on movement of residual contamination. Spatial and temporal changes in these boundary conditions are the primary factors that control the geometry and structure of a 
groundwater contaminant plume. Moreover, anthropogenic sources/sinks of water (wastewater discharges, outfalls, water line leaks, unlined evaporation ponds, groundwater injection and extraction wells, etc.) are often significant compared to natural infiltration (see Looney and Falta, 2000). Thus, the importance and influence of anthropogenic sources/sinks is amplified in arid settings. Considering hydrologic boundary conditions is often a useful extension to the site conceptual model to support interim and corrective measures for groundwater and serve as a critical framework for supporting LM decision-making. The overarching importance of the hydrologic framework for LM sites in arid climates is clearly demonstrated in the case study from the Tuba City and Gunnison sites are documented in this report.

\subsection{Geochemical Framework for Uranium Tailings Disposal Sites}

The geochemical evolution of a waste site is controlled by the history of disposal, the remediation history, and the natural conditions of the aquifer. Disposal and active remediation can be considered perturbations of the geochemical system. Some of these perturbations leave a lasting footprint in the form of changes to aquifer mineralogy. However, in general, the natural system works to alleviate the perturbation and return the system to near natural conditions.

The geochemical framework is related to the temporal, spatial, and hydrological frameworks. The temporal and hydrological frameworks are, in part, responsible for the nature of the geochemical framework. Yet, the feedback from the geochemical framework can influence the impact of the temporal framework, and the nature of the hydrologic and spatial frameworks. Within the geochemical framework, evolution of a waste site can be considered in terms of a series of migrating geochemical gradients (Denham and Vangelas, 2008). The gradients are created by actions within the temporal framework. Their rate of migration is a function of the aquifer mineralogy, background water chemistry, and processes within the hydrologic framework. The architecture of the spatial framework is, then, controlled by the migration rate of these geochemical gradients.

Disposal history is part of the temporal framework. The disposal history at UMTRCA sites can range from simple to highly complex. At the processing sites, there was generally a tailings pile that in some cases was accompanied by an adjacent evaporation pond. Leachate from these tailings piles contaminated the subsurface, often including the groundwater. The chemical nature of the leachate was determined by the chemical process used to extract uranium from the ore. Reactions of this leachate with aquifer minerals influenced the effects in the subsurface. For example, acidic leachate at many sites is buffered by the presence of natural calcite in the aquifer, minimizing the spread of acidic conditions. At some sites multiple processes were used, complicating the geochemical evolution of the site. The complexity of the evolution depends on the complexity of the temporal framework and the chemical composition of the various leachates.

The geochemical and hydrological frameworks interact in various ways. Groundwater flow drives migration of geochemical gradients, though the rate of migration depends on both groundwater flow rate and reactions of dissolved constituents with aquifer minerals. Different interactions occur at locations where groundwater exits the system. Within hyporheic zones, mixing of groundwater and surface water can result in reactions that include oxidation of reduced 
iron and degassing of carbon dioxide. In arid environments, a significant mass of water may exit the system as evapotranspiration resulting in precipitation of minerals at the capillary fringe. If water in the capillary fringe is contaminated, the contaminants may be deposited within these minerals. If the water table rises, some of the contaminants will be dissolved and re-introduced to groundwater. Likewise, during storm events, infiltrating water may dissolve the contaminants and carry them to groundwater. Another type of interaction between the hydrological and geochemical frameworks can occur when the mass of minerals dissolved or precipitated by contaminated groundwater interacting with aquifer minerals is sufficient to alter porosity and permeability of the aquifer.

Architecture of the spatial framework is influenced by interactions of contaminants with aquifer minerals. For strongly attenuated contaminants, the fringe of the plume may remain relatively close to the source. Conversely, when contaminants are poorly attenuated the impact zone and the transition zone may extend far from the source.

The key to understanding the geochemical framework is considering the whole system - both groundwater and aquifer minerals. There is a tendency to focus on the groundwater because it contains actively migrating contaminants and is often the only part of the system that is regulated. Nevertheless, it is reaction with aquifer minerals that often controls migration of contaminants. In addition, the changes to aquifer mineralogy by interaction with a contaminant plume can often explain features of the hydrological and spatial frameworks.

\subsection{Natural Attenuation Mechanisms - Uranium and Nitrate}

The complicated chemistry of uranium requires careful consideration of many possible species and minerals. Aqueous complexes may keep uranium mobile, but the wide spectrum of uranium minerals suggests some phases may exist that do the opposite and therefore can contribute to natural attenuation. At Tuba City, the calcareous nature of the aquifer sediments promotes uranium mobility by providing abundant dissolved carbonate species. Site documents discuss the dominance of anionic or neutral U(VI)-carbonate species that are unlikely to be significantly adsorbed by the negatively charged mineral surfaces prominent at $\mathrm{pH}$ values near 7 . In addition, equilibrium of calcite would promote formation of the neutral aqueous complex $\mathrm{Ca}_{2} \mathrm{UO}_{2}\left(\mathrm{CO}_{3}\right)_{3}(\mathrm{aq})$.

Nevertheless, even low partition coefficients (Kd values) can cause significant attenuation of uranium over long distances. Hence, adsorption may be a relevant attenuation process when evaluating transport times of uranium to downgradient exposure points.

There are natural reactions that can attenuate uranium migration by the precipitation of U(VI)bearing minerals. At UMTRCA sites where the uranium ore consisted primarily of carnotite $\left[\mathrm{K}_{2}\left(\mathrm{UO}_{2}\right)_{2}\left(\mathrm{VO}_{4}\right)_{2}\right]$, there is likely to be sufficient vanadium in leachate from the tailings to cause re-precipitation of carnotite near the tailings pile as leachate interacts with subsurface minerals. U(VI) can also coprecipitate with phosphate minerals, or adsorb to phosphate minerals and subsequently precipitate as U(VI) phosphates. Similarly, low concentrations of U(VI) are known to coprecipitate with calcite (e.g. Curti, 1999; Reeder et al., 2001). 
Less data are available on precipitation of U(VI) silicates, but their precipitation can attenuate uranium migration because of their very low solubilities. Figure 2 shows the stability fields of soddyite $\left.\left[\left(\mathrm{UO}_{2}\right)_{5} \mathrm{Si}_{2} \mathrm{O}_{9} \cdot 6 \mathrm{H}_{2} \mathrm{O}\right]\right)$ and uranophane $\left.\left[\mathrm{Ca}\left(\mathrm{UO}_{2}\right)_{2} \mathrm{Si}_{2} \mathrm{O}_{7} \cdot 6 \mathrm{H}_{2} \mathrm{O}\right]\right)$ relative to the hydrous $\mathrm{U}(\mathrm{VI})$ oxideschoepite $\left[\mathrm{UO}_{3} \cdot 2 \mathrm{H}_{2} \mathrm{O}\right]$ for the case in which groundwater is in equilibrium with calcite and quartz. Between $\mathrm{pH}$ values of 5 and 8 , schoepite is 1-3 orders of magnitude greater than the solubilities of soddyite and uranophane. Landa (2004) reviewed studies in which amorphous silica was observed associated with uranium mill tailings and suggests sorption of uranium by silica as an attenuation mechanism. Initial sorption may be the first step in precipitation of soddyite or uranophane. Kinetics of precipitation may often prevent the formation of these minerals from controlling uranium concentrations. However, they are common weathering products of surface exposed uranium (Frondel, 1958; Finch and Ewing, 1992)) and their precipitation should be considered as possible attenuation mechanisms.

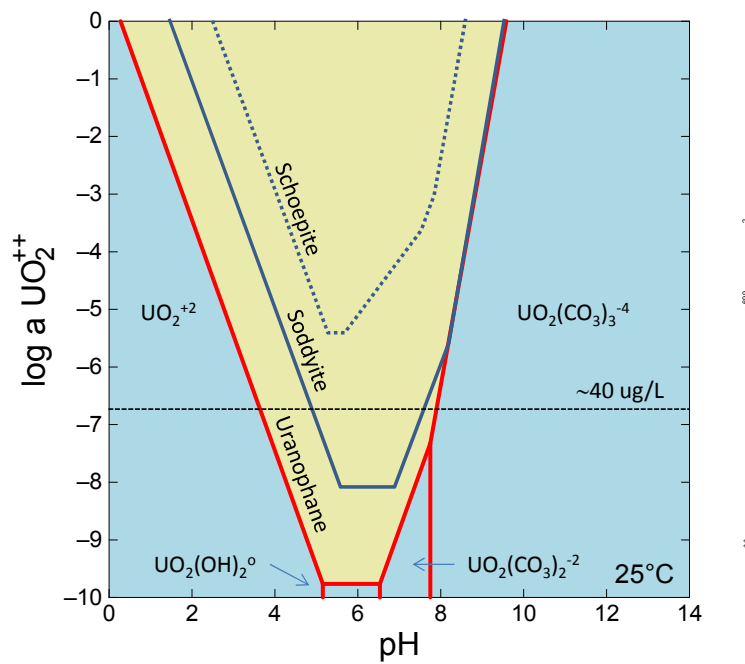

Figure 2: Stability of U(VI)-silicate minerals relative to schoepite; in equilibrium with calcite, quartz, atmospheric PO2, and $\mathrm{PCO} 2=0.01$ atmospheres.

The most widely studied attenuation mechanism for uranium is reduction of U(VI) to U(IV). This may be possible locally, but the prevailing thought is that uranium remains oxidized (DOE 1998). If there are significant concentrations of ferrous iron or low redox potential measurements recorded at Tuba City, localized reduction of U(VI) should be considered. Figure 3 shows the stability of uraninite with the equal activity line for the ferrous-ferric iron couple. It suggests that if there is significant ferrous iron in the groundwater, conditions conducive for reduction of $\mathrm{U}(\mathrm{VI})$ to $\mathrm{U}(\mathrm{IV})$ would exist at a $\mathrm{pH}$ values between 5.5 and 8.0. 


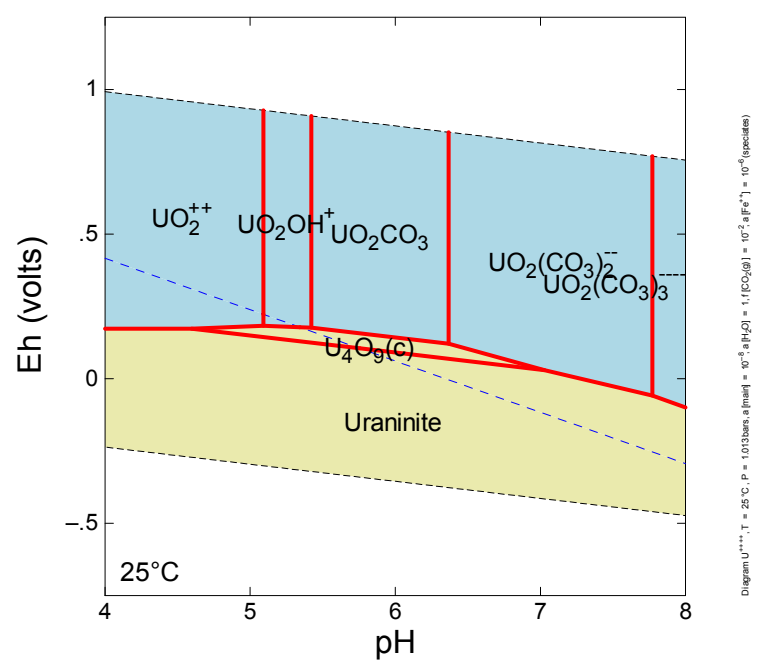

Figure 3: Stability of U(IV) phases with equal activity line for the ferrous-ferric iron couple (dotted line).

\section{$\underline{\text { Nitrate }}$}

The primary attenuation mechanisms for nitrate are biological uptake by plants and microbial degradation. In locations where plant roots can reach the water table, nitrate will be removed from the groundwater as an essential nutrient. If significant ferrous iron concentrations occur in the groundwater, it is possible that microbial mediated reduction of nitrate could occur.

\subsection{Active Remediation Strategies for Uranium}

Enhancement of uranium attenuation is possible by emplacing reagents or amendments into the aquifer that react with and sequester uranium. These treatment zones can be emplaced by injection or excavation and fill. Injection can be done with liquid and particle amendments, though particles generally require more closely spaced injection points. One strategy for emplacement is to treat "hot spots" within a plume. Alternatively, linear installations can be completed across plume flow lines creating a permeable reactive barrier.

The most effective types of amendments are those that work with and not against the natural geochemistry of the system. Reductive systems for uranium treatment have been studied extensively, but work against the prevailing geochemistry in aerobic systems and are always subject to re-oxidation. Though it is possible they can be engineered to release uranium very slowly upon re-oxidation, the burden of proof required to demonstrate that there is no risk from future re-oxidation is onerous.

Methods of sequestering U(VI) requiring no reduction are available for use in aerobic systems. The most studied and field tested involve phosphate amendments. Strong sorption of uranium to the mineral hydroxyapatite has been demonstrated (Jeanjean et al., 1995; Arey et al. 1999; Knox et al., 2008)). The least expensive source of apatite is "rock phosphate", mined in many locations within the United States. One drawback of this source is that it tends to contain natural uranium. Biological sources of apatite may be more expensive but do not contain significant 
concentrations of uranium. Apatite II ${ }^{\mathrm{TM}}$, derived from fish bones, is a commercial source of apatite that has been demonstrated in the laboratory and field to strongly sorb uranium (Raicevic et al., 2006)). Phosphate can also be introduced to the subsurface in liquid form (e.g., Shi et al., 2009). If only dissolved phosphate is injected, effectiveness depends on mixing with the uranium-bearing groundwater or on reactivity of phosphate ion sorbed to subsurface minerals. An apatite permeable reactive barrier targeting Sr-90 was installed at Hanford by injection of dissolved phosphate and Ca-citrate (double-check reagents). Precipitation of apatite was confirmed and Sr-90 is currently being removed from groundwater, though downgradient Sr-90 concentrations are beginning to increase. One possible problem with apatite-based technologies is the tendency of less reactive fluorapatite to coat the hydroxyapatite particles rendering them less effective. A possible problem for all phosphate-based technologies is that phosphate also forms strong aqueous complexes with uranium. Hence, conditions must be conducive to sorption or precipitation of uranium and not solely aqueous complexing by dissolved phosphate.

There are additional amendments that may be useful for enhancing uranium attenuation in groundwater. However, they are in the development stage and have not been extensively field tested. Currently, the Savannah River National Laboratory is testing U(VI)-silicate and U(VI)humate technologies. Field tests of the humate technology are ongoing and follow the laboratory studies of (Wan et al. 2011). The silicate studies are in conjunction with Florida International University and are focused on the uranium-silica chemistry discussed above. Takunaga et al. (2009)have demonstrated in laboratory studies that vanadate solutions can force the precipitation of carnotite $\left.\left(\mathrm{K}_{\left(\mathrm{UO}_{2}\right)}\right)\left(\mathrm{VO}_{4}\right)\right)$. This may be a viable remediation strategy if injection of vanadium into the subsurface is acceptable to regulators and stakeholders.

\section{Observations on Active Remediation Strategies at Tuba City}

- For injection strategies to be viable at Tuba City, the cause of limited production of many of the extraction wells in the pump-and-treat network at Tuba City would have to be well construction problems rather than formation issues. If there are formation issues, injection of amendments would not be cost effective.

\subsection{Monitoring}

A significant challenge faced by the LM program will be to optimize the performance and manage the cost of long term monitoring at their sites. LM should consider implementing a periodic, technical review of their long term monitoring actions to ensure that the performance of monitoring system is effective and meets the regulatory commitments. Significant improvements have been made to that optimize monitoring programs through the application of statistical techniques and improved analytical approaches. These techniques can be used to identify opportunities to reduce costs associated with the existing infrastructure, specifically, reducing the number of wells sampled, contaminants analyzed, monitoring frequency, and reporting requirements without impacting the quality of the program. More importantly, a periodic evaluation should be made to ensure that the current monitoring strategy is designed to identify and monitor key uncertainties that are consistent with the current phase of the remediation project. Specific objectives of the periodic review might include: 
- Evaluation of monitoring objectives to determine if they are consistent with the current phase of the remediation project and status of the plume.

- Identification of approved regulatory requirements for comparison with current monitoring portfolio.

- Evaluation of the spatial coverage of well networks compared to current extent of contamination.

- Evaluation of groundwater plume geometry through time, as static plumes require less spatially intensive monitoring.

- Evaluation of time trend data at individual wells. Based on many of the plumes having consistent and established trends, proposals can be made to reduce the frequency of sampling.

Structured evaluations such as these that are focused on optimization of existing well networks typically can provide costs savings on the order of 10 to 20 percent in the overall cost of monitoring. As an example, a comprehensive review of groundwater monitoring and reporting was done at SRS in 2012 and the recommendations if accepted by regulatory agencies would result in cost savings of $\$ 250,000$ to 500,000 per year (SRS, 2012). The document provides the technical justification for the proposed optimization and a pathway for regulatory approval of the changes.

Implementation of Innovative Approaches for Long Term Monitoring

Boundary conditions are the overall driving forces that control groundwater and plume movement at a given site and include metrics associated with meteorology, hydrology, hydrogeology and land use. Since long term monitoring will be required for decades at UMTRCA sites, changes in boundary conditions are the most likely cause of unexpected deviations in plume behavior, and are relatively easy to monitor and measure. Much of the data is available from public databases. Careful consideration should be given to assessing the impact of boundary conditions on periodic basis.

Examples include:

- New installations or changes in the operation of existing municipal and agricultural wells near the site can cause changes in groundwater velocity and direction leading to high variability in monitored parameters

- Demolition of existing infrastructure or installation of new infrastructure including roads, ditches, buildings etc. can significantly impact groundwater flow dynamics

- Changes in the rate or amount of discharges to injection wells or trenches

- Adjacent industrial activities such as gravel mining or other industrial process can impact subsurface systems

Changes in the boundary conditions can result in changes the groundwater flow dynamics and impact the overall monitoring program. Over time, monitoring locations (both the areal location and depth of sampling) may no longer be in the correct locations which can create variability in measurements and false or non-representative trends. Robust conceptual site models should include scenarios for changes in boundary conditions or be periodically updated to include new 
boundary conditions. Much of the boundary condition data can be easily obtained and updated with cordial, cooperative agreements between stakeholders.

In addition, current research efforts are underway at SRNL and other research facilities to develop new cost effective, protocols for long term monitoring. Sample strategies include the measurement and substitution of master variables such as chemical surrogates for some of the contaminant measurements. Master variables control the chemistry of the groundwater system, and include redox variables (ORP, DO, chemicals), $\mathrm{pH}$, specific conductivity, biological community (breakdown/decay products), and temperature. Significant changes in these variables will result in conditions whereby the plume may not be stable and therefore can be used to predict possible plume migration. Conversely, concentration measurements for all types of contaminants in groundwater are a lagging indicator plume of movement - significant changes indicating that contamination has migrated. A robust suite of tools is commercially available to measure most of these variables. 


\subsection{Site Specific Observations and Recommendations - Tuba City}

\subsection{Approach}

In the following sections we work through some of the frameworks, topics and issues that are specifically relevant to the former Tuba City Processing site (Figure 4). In preparing this material, the team determined that the relative significance of the different sections varied widely. Therefore, we have purposely and commensurately varied the length, level of detail, and number of technical references. In the most detailed sections, key points are highlighted in text boxes to summarize and emphasize the most significant concepts. At the end of each section, a narrative that provides topic specific recommendations is provided.
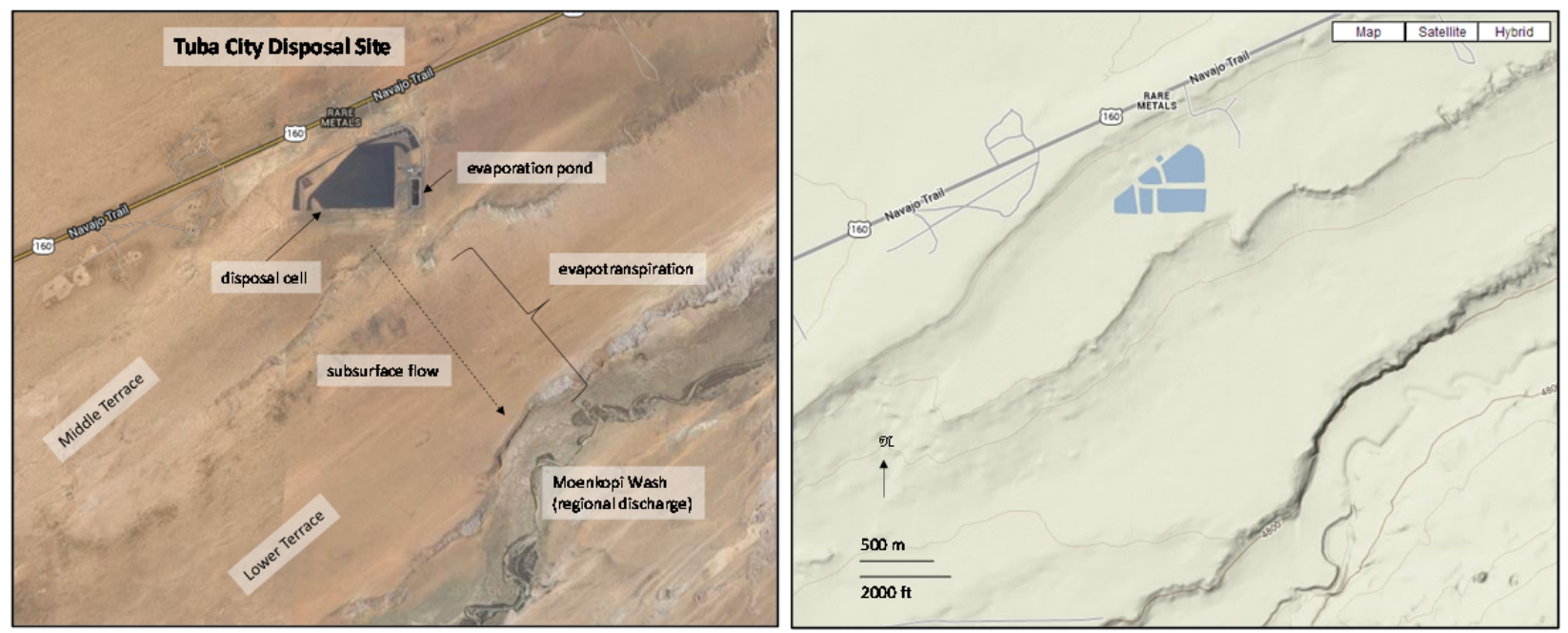

Figure 4. Tuba City: former processing facility and disposal cell -- current configuration (left) and regional topography (right)

\subsection{Tuba City: Hydrologic Conceptual Framework}

In all groundwater systems, water flows from sources (areas where water enters the subsurface) toward sinks (areas where water exist the subsurface). Below the water table, a traditional tool is evaluation of groundwater paths from sources to sinks. This path is depicted as a flow line. The result is a powerful conceptual model in which one can visualize where any parcel of water will discharge. Within the subsurface the precise path of each flow line is driven by the strength and relative locations of the sources and sinks and the hydro-lithological characteristics of the aquifer. As shown in Figure 5, nested flow nets are typical in deep/extensive systems (Fogg and Senger, 1985). Shallow flow lines move from local sources to local discharges and deeper flow lines move toward regional discharges. Importantly, there is little mixing of the flow lines so that water in the shallow flow zone will not interact with the deeper regional flow. If contamination is present in the shallow flow zone, it will flow toward the local discharge and not the regional discharge. 


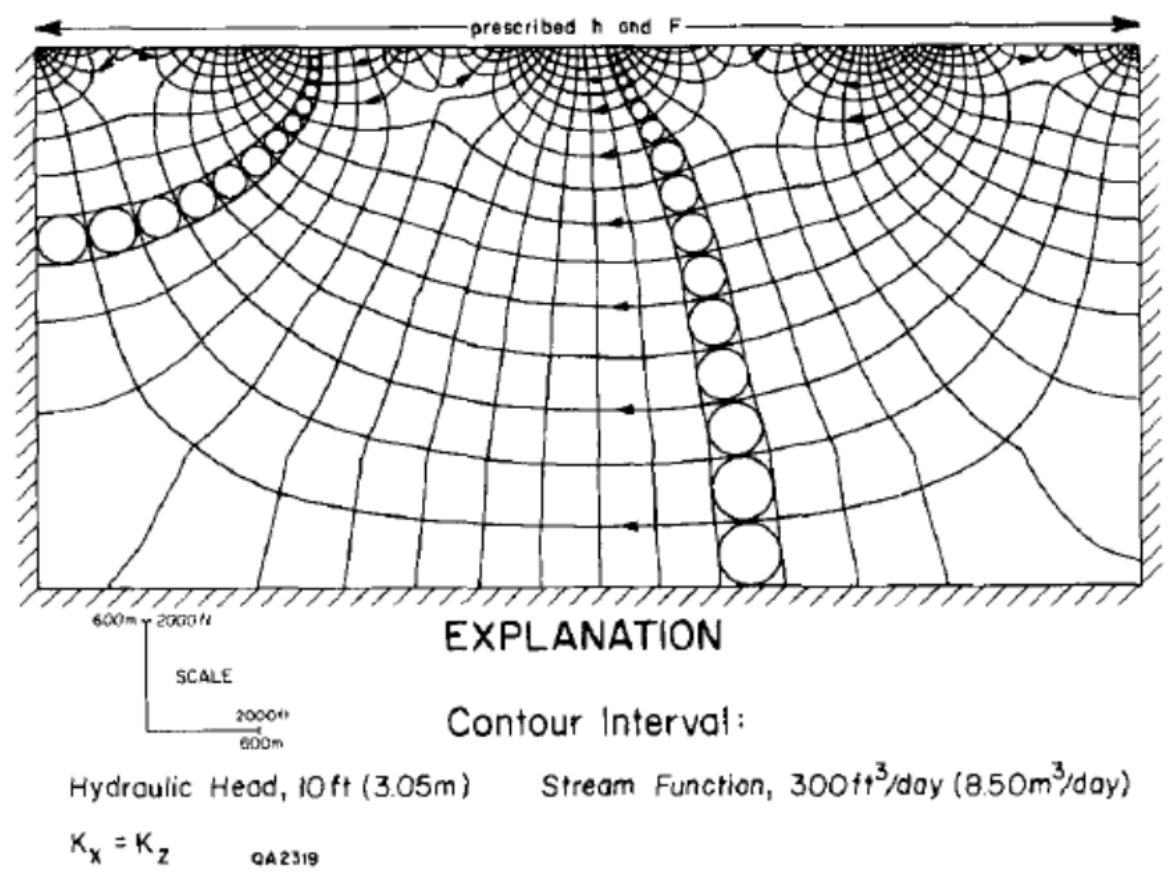

Figure 5. Example nested flow lines for a site with local and regional water sources and sinks

In Figure 6, this general flow line concept has been overlain on the existing LM Tuba City site cross section. The former processing facility and zone of highest groundwater contamination are depicted along with the topography. The figure is annotated to show various areas of water discharge or loss. In this figure, some of the key flow lines are depicted - the potentially contaminated flow lines are color coded. The figure also demonstrates the general power of a flow net approach in providing site specific insights. Local flow is depicted as water moves from the former processing site to seepage and evapotranspiration areas in the lower terrace and in the terrace transition areas. Deeper regional flow lines are not impacted by the contaminants -- unimpacted ancient water is projected to flow beneath the site toward Moenkopi Wash.

\section{Key Points:}

Where does the contaminated water flow at Tuba City?

Contaminated water beneath the former processing site flows in the uppermost portion of the aquifer and exits as it flows into and beneath the lower terrace. In this arid to semi-arid setting, shallow groundwater is transferred into the vadose zone and atmosphere via evaporation, transpiration and seepage. The water flowing to Moenkopi Wash is from the deep uncontaminated portion of the aquifer. 


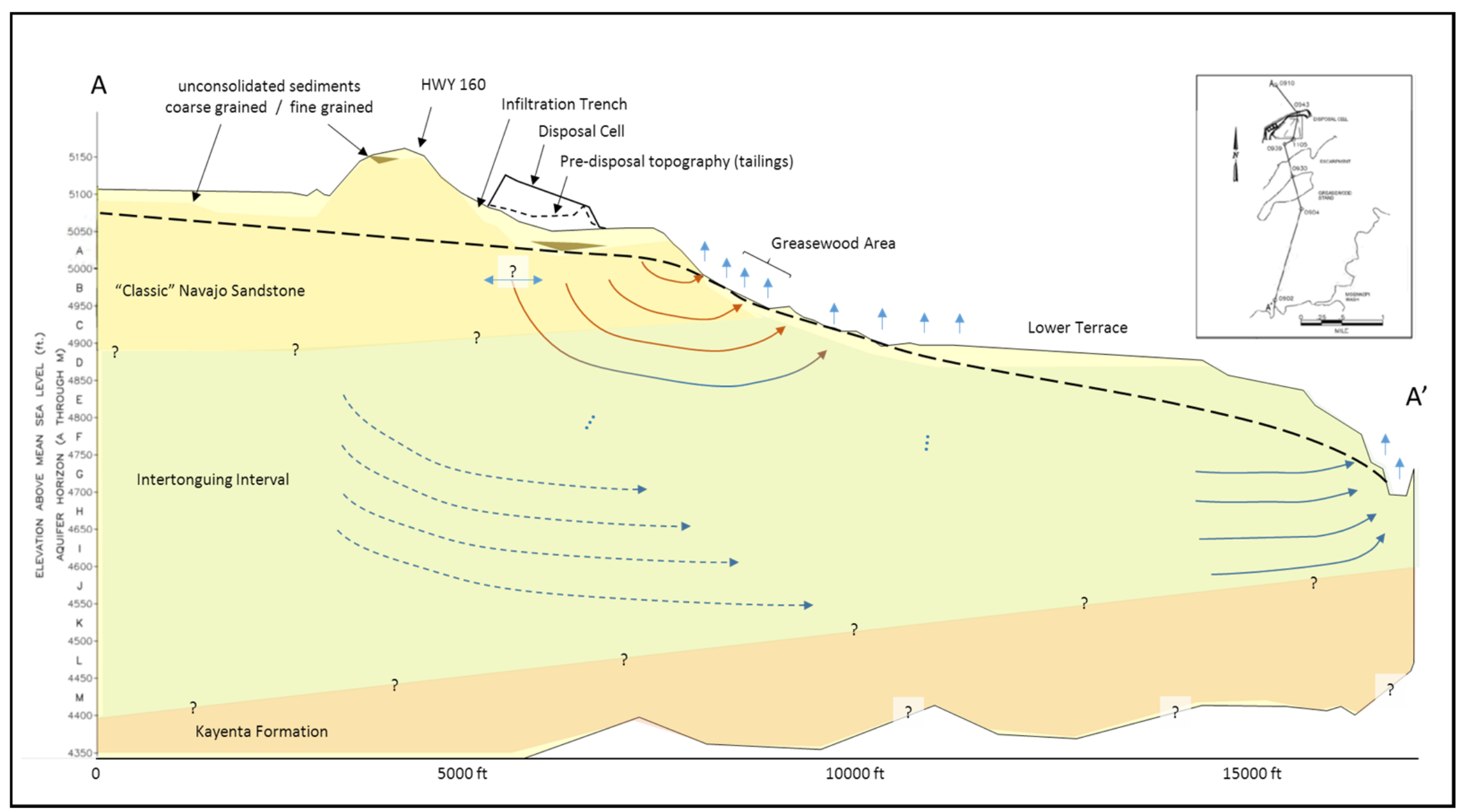

Figure 6. Hydrogeologic cross section with key flow lines depicted; brown lines approximate the path of contaminated water. 


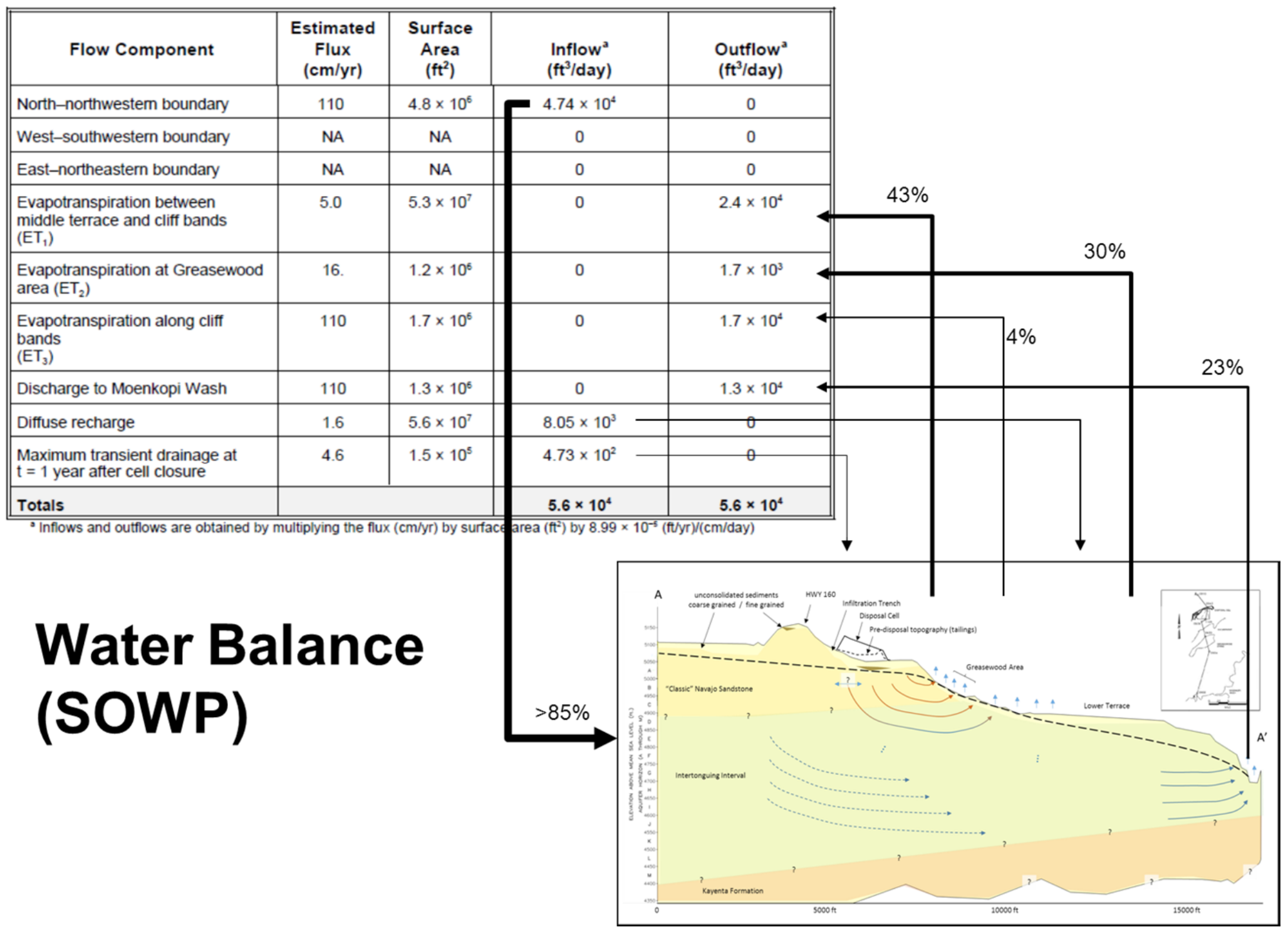

Figure 7. Water balance in the original Site Observational Work Plan as it relates to the cross section 
Based on this conceptualization, evapotranspiration and seepage along the path of the plume are important parameters that control and limit the extent of the plume in this arid environment. According to the Final Site Observational Work Plan (SOWP, MACTEC, 1998) for this site: “...the entire area between Moenkopi Wash and the middle terrace is essentially a ground-water discharge area via ET. The ET is dominated by transpiration across the lower terrace and the slope between the middle and lower terraces..." These conclusions were based on a variety of methods, including surveys of desert phreatophytes (plants that extract groundwater from depths up to about $10 \mathrm{~m}$ ), climate data, the scientific literature, and engineering calculations. The data were organized into a water balance that is depicted in graphical form in Figure 7. The primary input of water into this system $(>85 \%)$ flows laterally into the cross section from the left and flows under the former Tuba City Site. Note that only $23 \%$ of the water in the cross section exits at Moenkopi Wash (so that all of the local infiltration and the bulk of the lateral inflow are lost to evapotranspiration between the middle terrace and Moenkopi Wash). Evapotranspiration is such an important component of the water balance that additional focused studies would be useful to confirm rates. At this particular site, however, the available information indicates that the extent of the contaminated plume will be limited and that is improbable for contaminants to reach Moenkopi Wash. This conclusion would be unchanged if the fraction of water lost to evapotranspiration is anywhere in the range of approximately $20 \%$ to $100 \%$.

As described above, hydrology theory and early technical studies at Tuba City indicate that water originating at the former processing site is expected to discharge as evaporation, transpiration and seepage - an important related question is the fate of the constituents dissolved in the water. Fortunately the behavior of dissolved constituents in this scenario are described in a number of journal articles and reports (Alonzo-Zarza and Wright, 2010; Arakel and D. McConchie, 1982; Carlisle, 1978 and1980; Jutras, et al., 2007; Mann and Horwitz, 1979; Purvis and Wright, 1991; Spotl and Wright, 1992). This supporting literature documents precipitation and accumulation of minerals such as calcite and gypsum in arid and semi-arid settings. Figure 8 summarizes a conceptual model of the dynamic processes that occur in the vicinity of the near-surface water table in areas of evapotranspiration and outcrop.

On a landscape scale, the mineral accumulations occur as water flows laterally into valleys and outcrops where the solution is concentrated by evaporation, transpiration and seepage (Alonzo-Zarza and Wright, 2010). In some areas the minerals solidify into cemented zones of subsurface calcretes or gypcretes; in other areas these minerals can precipitate at the surface following seepage. When minerals are formed as a result of lateral groundwater flow and the processes depicted in Figure 8 they are described as "non-pedogenic" in origin (i.e., they are not associated with surficial soil forming and weathering processes that progress downward from the ground surface). 
Non-pedogenic calcretes and gypcretes have been identified and characterized in Australia, Europe, Africa, and (notably) in the western United States and Canada. As documented in mineral exploration surveys of broad uncontaminated areas, these accumulation zones contain the major constituents (calcite and/or gypsum) along with accessory minerals containing elements such as uranium (e.g., Peterson et al., 1985; Carlisle, 1978 and 1980).

Importantly, the topography and regional groundwater condition at Tuba City is closely akin to the sites where non-pedogenic mineral accumulation has been documented. Thus, dissolved constituents in the water originating at the former processing site would be expected to accumulate as solid minerals near the terminus of the local groundwater flow paths and those minerals should be similar to natural minerals accumulating in nearby areas. Importantly, the mineral accumulation processes should result in relatively clear geochemical signatures and patterns that can be tested and confirmed using low cost sampling and analysis methods.

The mechanisms depicted in Figure 8 are described in more detail below.
Key Points:

Where do the groundwater contaminants go?

In areas of groundwater evaporation, transpiration or seepage, dissolved constituents in the groundwater will precipitate and accumulate as common minerals such as calcite and gypsum. Primary accumulations will be in the deep vadose zone (near the capillary fringe), around the roots of phreatophyte plants, and near surface water seeps. Contaminants will occur as trace accessory minerals in the accumulation areas. The expected mineral assemblage would be similar to naturaluncontaminated deposits of calcite or gypsum in this arid to semi-arid region. 
a)
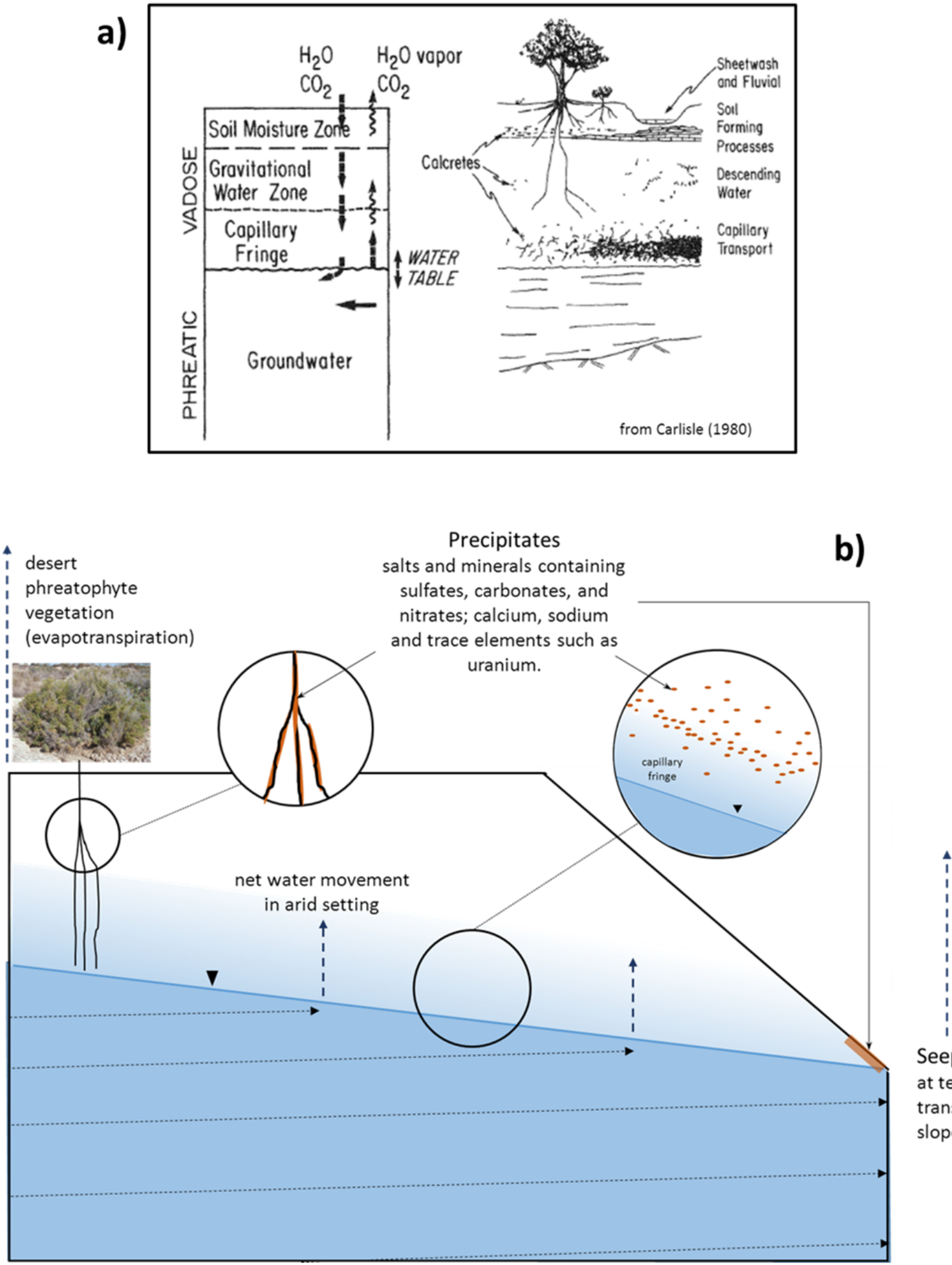

Seeps

at terrace transition slopes

Figure 8. Key geochemical processes associated with non-pedogenic mineral accumulations in arid and semi-arid settings - a) general concept and b) annotated to highlight probable mineral accumulation zones for Tuba City 
In arid to semi-arid climates, desert phreatophytes extract water and the associated dissolved constituents. For areas located above the plume, the extracted water would contain nitrate (a nutrient), sulfate, calcium and sodium (elements familiar to desert plants), and trace elements including uranium. Data from plant uptake studies presented in the SOWP (MACTEC, 1998) indicates that the groundwater concentrations observed in the lower terrace will not adversely impact plant growth and will not accumulate to harmful concentrations in plants. A survey of the plants present in the lower terrace (MACTEC, 1998) documented the presence of both obligate phreatophytes (plants that must access groundwater to live) and facultative phreatophytes (plants that can, but do not have to, access groundwater). These desert plants have evolved a number of mechanisms to limit the uptake and accumulation of dissolved constituents extracted from groundwater; for example, Purvis and Wright (1991) document that dissolved constituents are liberated from the water during transport to the surface and that significant mineral accumulation occurs in the vicinity of the deep roots of desert phreatophytes sometimes forming "rhizocrete" deposits associated with root masses (Figure 8).

In addition to the phreatophyte extraction, groundwater can be lost as a result of capillary flow and evaporation. These abiotic physical processes result from gradients of liquid phase and vapor phase moisture in the vadose zone - moving from the capillary fringe toward the atmosphere. These gradients will result in a net loss of water and chemical precipitation of dissolved groundwater constituents as solid salts and minerals. When the water table is close to the ground surface (such as areas near seeps), capillary forces will dominate (Tyler et al. 2006) and draw liquid water to the surface where it can evaporate and leave mineral precipitates. In areas where the water table is deeper (e.g., 5 to $10 \mathrm{~m}$ and below), capillary forces combined with vapor phase diffusion result in mineral precipitation in the vicinity of the capillary fringe. While all of these solids are subject to episodic weathering (dissolution and re-precipitation), they are relatively inert materials. As noted above, the mineral assemblages would be expected to be similar to naturally occurring calcite and gypsum deposits. The minerals associated with roots of phreatophytes and those near the capillary fringe are effectively "trapped" in the deep vadose zone where they would not impact the surface environment or Moenkopi Wash. As part of any characterization, it would be prudent to characterize any plume related minerals (location and nature) to support site assessment and to assure that these materials do not pose significant risks to humans, livestock or ecology.

To evaluate the major mineralogy that might be expected at Tuba City from loss of water at the capillary fringe The Geochemist's Workbench (Bethke and Yeakel, 2012) was used to simulate the process. The process was divided into two steps - degassing of $\mathrm{CO} 2$ to equilibration with atmospheric $\mathrm{CO} 2$ and evaporation of water. Simulations were run using analyses of a background well (Well 0901) and a plume well (Well 0934) listed in DOE (2012) and assuming one kilogram of groundwater. Figure 9a shows that CO2 degassing causes minor precipitation of calcite in the water from the background well and precipitation of considerably more (about two orders of magnitude more) calcite in groundwater from the plume. The water composition and mineralogy from the first step 
were input into the evaporation step in which $98 \%$ of the water was evaporated. The results are shown in Figure 9b. The only mineral precipitated during simulated evaporation of the background water was additional calcite. Gypsum precipitation dominates the mineralogy during simulated evaporation of water from well 0934. For each liter of water with this approximate composition lost to evapotranspiration, 2.5 grams or approximately $1 \mathrm{~cm}^{3}$ of gypsum is produced. This suggests that non-pedogenic calcretes are likely present in background areas marking elevations of old water tables while in the plume area a significant gypcrete is expected due to elevated sulfate concentrations. Minor minerals would also be expected and may contain significant concentrations of uranium. These were not simulated because the high ionic strengths produced by evaporation limit the simulation to major dissolved ions.

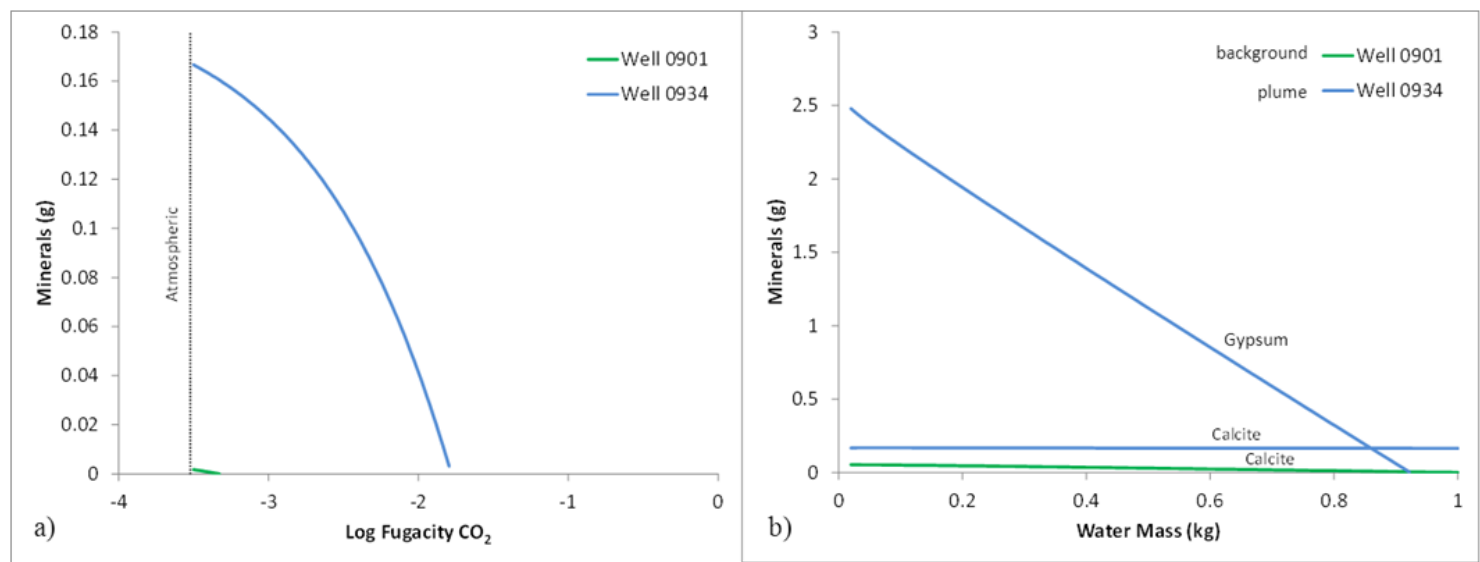

Figure 9: Minerals precipitated during simulated degassing(a) and evaporation(b) of background and contaminated groundwater at Tuba City.

In summary, the capacity of the earth to limit the size of the groundwater plume and to naturally attenuate and detoxify the latent environmental groundwater impacts of the former Tuba City processing operations results from a combination of the desert plants and net evaporation along the flow path between the middle terrace and Moenkopi Wash and the associated geochemistry. Flow net analysis demonstrates that contaminated water is isolated in the shallow section of the aquifer and that deeper water flowing to Moenkopi Wash will be ancient water flowing from distant areas. As the water flows into and beneath the lower terrace, dissolved constituents are expected to accumulate as solid minerals in the vadose zone and near seeps. 


\section{Recommendations based on the Hydrologic Conceptual Framework}

Confirming and accounting for the key features of the hydrologic conceptual framework are critical to developing a long term strategy for Tuba City and the other UMTRCA sites that is both effective and efficient. Moreover, the discussion above highlights the importance of this conceptual framework for almost all LM sites, particularly those in arid settings where the impacts of small changes in hydrologic boundary conditions are relatively important on an absolute basis. For Tuba City, we recommend collecting targeted information to confirm the conceptual model described above, revising the site conceptual model based on the data, and incorporating the improved understanding into plans for future site clean-up, management, and transition to beneficial use.

\subsection{Tuba City: Spatial/Temporal Framework}

As described in the previous section, the hydrologic conceptual framework at Tuba City provides overarching controls on the spatial extent of the plume and limits the development of the traditional plume zones. Thus, the most appropriate spatial/temporal framework for this site focuses on changes over time and the evolution of the site. There are a number of approaches to developing a temporal framework for a site. In the case of Tuba City, the defining broad periods, or stages, that describe operation and recovery is potentially useful - within a stage, the general activities at the site were relatively stable, while the activities changed substantially from one stage to the next. Note, that this does not imply that things do not change within a stage (e.g., the extracting solution was changed from acid to alkaline carbonate during operation) nor that conditions are static during a period. Over time, the site has gone through a number of temporal changes as shown in Figure 10, including a "Baseline / Pre-Operation Stage" (not shown), a "Disposal / Pre-remediation Stage," a "Tailings Remediation / Transition Stage," and a "Post Remediation/Recovery Stage."

During the "Baseline Stage" (prior to any processing operations), unimpacted groundwater flowed beneath the site toward local evapotranspiration (ET) boundaries and regional discharges. During this period, natural mineral formation processes associated with uncontaminated groundwater beneath and downgradient of the site would have occurred in the vadose zone (e.g., above the capillary fringe) and near seeps.

During operation of the uranium ore milling and extraction operations (the "Disposal / Pre-remediation Stage"), the subsurface received liquid discharges associated with slurried tailings disposal, process and sanitary wastes, and infiltration from unlined collection/evaporation ponds. The intensity, chemistry and locations of liquid discharges varied during this period. For example, an acid solution was initially used for the uranium extraction and the process was altered to use an alkaline carbonate solution in the later years. This change in chemistry is currently reflected in the spatial pattern of chemistry in the contaminated groundwater beneath and downgradient of the former processing facility. During this period, on-site infiltration into the subsurface would be higher than baseline levels, particularly in areas of active slurry disposal or beneath unlined basins. 


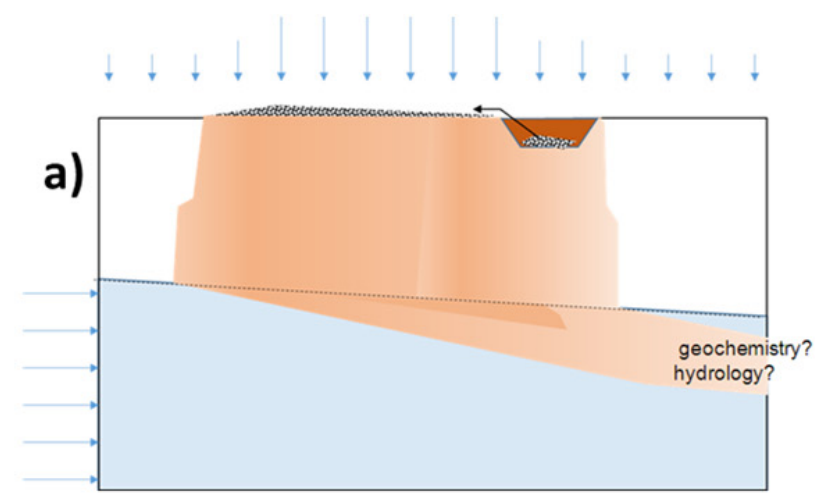

Disposal / Pre-remediation Stage

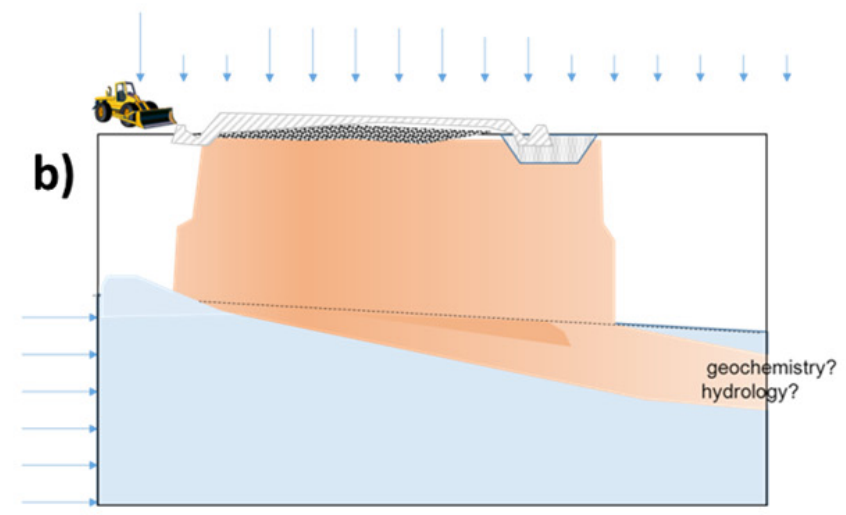

Tailings Remediation / Transition Stage

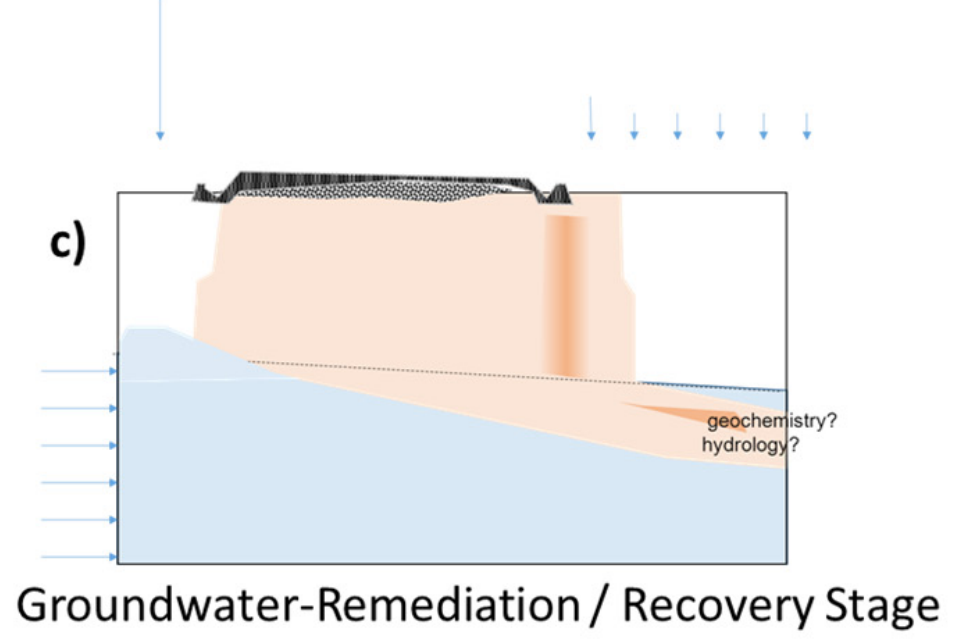

Figure 10. Simplified temporal framework for the stages at the former Tuba City Processing Site 
During a period of active on-site remediation (the "Tailings Remediation / Transition Stage"), liquid discharges to the subsurface were primarily associated with water needed to perform the closure activities (e.g., consolidating wastes, isolating the tailings, compacting barrier layers, and dust suppression). As a transition from this stage, water beneath the stabilized tailings would drain slowly from the vadose zone with the eventual conditions of water distribution and flow governed by capillary forces. The water exiting the vadose zone will serve as a transient decaying source of contaminants into the groundwater flowing beneath the stabilized tailings cell. As with the previous stage, onsite infiltration into the subsurface would be higher than baseline levels; in this case, focused in areas of intensive closure activities.

Following stabilization of wastes and tailings, "upgradient" groundwater will flow into the site and eventually flush through the plume. This is the transition to the "Groundwater Treatment / Recovery Stage." In the case of Tuba City, a pump and treat system that extracts contaminated water, distills the water to generate clean portion $(>90 \%)$ and a brine $(<10 \%)$ for evaporation. The clean distilled water is returned to the aquifer using an upgradient infiltration trench. Re-infiltrated water (and natural upgradient water) is projected to flow beneath the site and flush the plume. During this period, on-site infiltration into the subsurface would be generally lower than baseline levels, particularly in areas of stabilized tailings. Operation of the pump and treat system would result in the redistribution of groundwater and water table mounding in the area of the infiltration trench.

Unfortunately, the timeframe for the flushing required to meet drinking water standards in the most contaminated portions of the plume is expected to be long. This timeframe is impacted by a number of factors that are well documented in the literature. One of the most important challenges is the natural heterogeneity in aquifer systems and the presence of flow paths that are more (or less) active. The active flow paths will flush relatively quickly, but less active flow paths (contaminated over a long period of time) will continue to discharge contaminants into nearby active flow paths and generate potentially significant plume concentrations for many pore volumes (see Sale et al. 2008). For mobile contaminants, measurable concentration reduction trends are typically observed after one pore volume but many pore volumes are often needed for the plume to restabilize and/or achieve remediation goals. Importantly, based on the documented groundwater flow rates and conditions at Tuba City, there has not been enough time for even one flushing volume of the groundwater to pass beneath the tailings; therefore, no declining trend in downgradient monitoring wells would be expected at this time, even for mobile contaminants.

Key Point:

There has been insufficient time for the pump and treat to remove one groundwater flushing volume beneath the tailings so that no definitive conclusion based on a "lack of trend" in downgradient wells can be made. 
Further complicating the recovery, many of the contaminants present in the plume are not fully mobile so that a number of other limiting factors, such as sorption, also contribute to plume persistence and tailing. Of particular importance for this site is the presence of contaminants (such as sulfate or uranium) in precipitated mineral phases within and above the plume. These minerals will dissolve over an extended time period and will result in elevated concentrations of any major or minor elemental constituents until the solid phases are depleted. Varying water table elevations, such as mounding near the infiltration trench of the pump and treat system, will inundate sediments in the deep vadose zone and may result in dissolution of solid phases that would normally be above the water table. As a result of the combined impacts of all of these factors, the near-field plume beneath the former Tuba City mineral processing facility is expected to persist for 10 or more pore volumes. Based on the observations, the original conceptual design based on one or two pore volumes is unrealistic.

\section{Recommendations based on the Temporal Conceptual Framework}

In the case of Tuba City, the temporal framework serves primarily as a tool to inform a more robust and nuanced geochemical framework (e.g., by emphasizing the important influences of the different ore extraction fluids in different areas of the site). For the "Groundwater Remediation and Recovery Stage", the temporal framework provides important context to expected-realistic timeframes for groundwater recovery. Importantly, the extended timeframes described for the near-field plume result from fundamental processes in the environment and are somewhat insensitive to the selected remedial technology. Importantly, the hydrologic framework presented above suggests that the ET boundary and associated processes may limit the plume extent and isolate the contamination. We recommend that LM incorporate this information as they work with regulators and stakeholders to develop and implement a long term strategy to address the contaminated groundwater and to assure that the contamination does not adversely impact the surrounding environment.
Key Points:

Natural heterogeneity, sorption, solid mineral dissolution, and other factors will sustain high plume concentrations in the near-field groundwater for an extended timeframe requiring many flushing volumes. While the site is expected to trend toward baseline conditions over time, the period required to reach remedial action objectives throughout the near-field plume for all contaminants is expected to be many decades. 


\subsection{Tuba City: Geochemical Framework}

The disposal history for the Tuba City site is complicated resulting in a time dependent geochemical framework that includes:

1. Acid infiltration from the original uranium extraction process

2. Alkaline infiltration from the later carbonate extraction process

3. Background water flushing between the end of ore processing and beginning of remediation

4. Transient drainage following construction of the disposal cell

5. Flushing by treated water discharged to the infiltration trench

Additional complexity was introduced by the varied nature of the ore processed at Tuba City. Chenowith $(1986,1993)$ report the history of ores processed at Tuba City. Variations in the lime content, vanadium content, and concentrations of other minor elements would have caused variations in the composition of the slurries deposited on the tailings pile. However, the large size of the tailings pile likely diminished any significant effect of these variations on fluids infiltrating the subsurface.
Key Point:

Tuba City has a complex perturbed geochemistry associated with the original acid and alkaline extraction processes and disposal of tailings slurries.

The aggressive fluids associated with the uranium processing and transient drainage dominate the geochemical framework. The geochemical conceptual model outlined in DOE (1998) posits that the acidic sulfate-rich fluids infiltrating from the tailings pile caused dissolution of calcite and replacement of gypsum (Figure 11a). This is consistent with the gypsum saturation zone highlighted by Morrison (1996). When the uranium extraction process switched from acid extraction to carbonate extraction, infiltration into the subsurface would have been a high $\mathrm{pH}$ solution with high concentrations of carbonate. Under these conditions, it is thermodynamically feasible that calcite would replace some of the gypsum (Figure 11b).

Groundwater chemistry data from 2012 (DOE, 2012) indicates that gypsum saturation still prevails within the plume (Figure 12). Figure 12 shows groundwater chemistry from select background wells (0901 and 0910), wells within the plume (0940, 0941, 0906, 0908, 0262, 0265, 0267, 0263, and 0934), and a well at the downgradient fringe of the plume (0282). The diagram was constructed for conditions representative of groundwater within the plume. The red dotted line shows how the stability fields change under background conditions. Most of the plume wells are in equilibrium with gypsum. The background wells are close to saturation with calcite, but are well below saturation with gypsum as indicated by their proximity to the red dotted line. Background conditions are appropriate for well 0282 and its position on Figure 12 indicates water from this well is saturated with calcite but undersaturated with gypsum. 


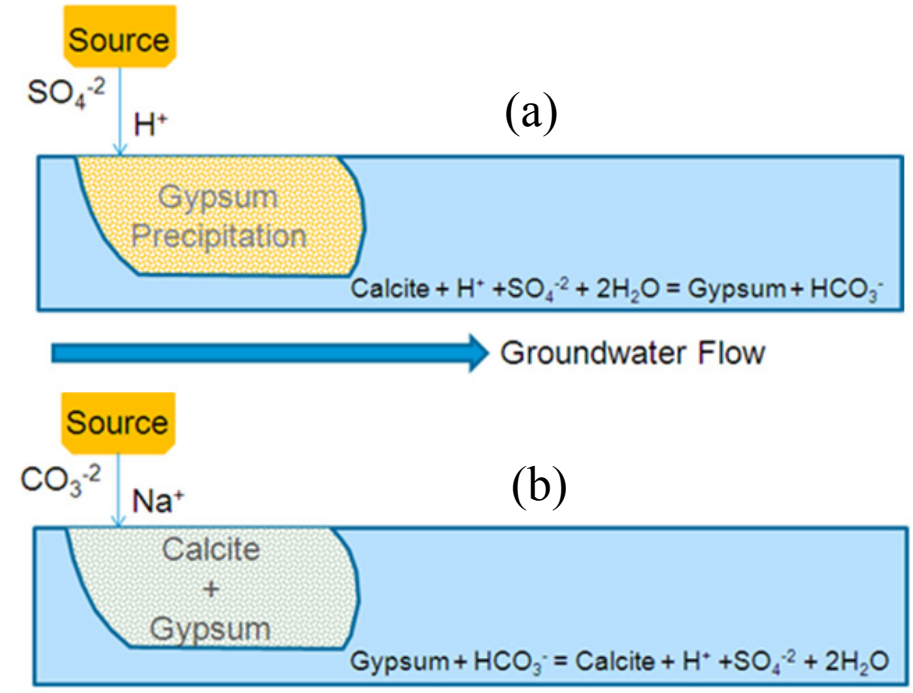

Figure 11: Diagrams showing possible scenario for infiltration of sulfuric acid process fluids into aquifer with natural calcite (a) followed by infiltration of sodium carbonate fluids (b).

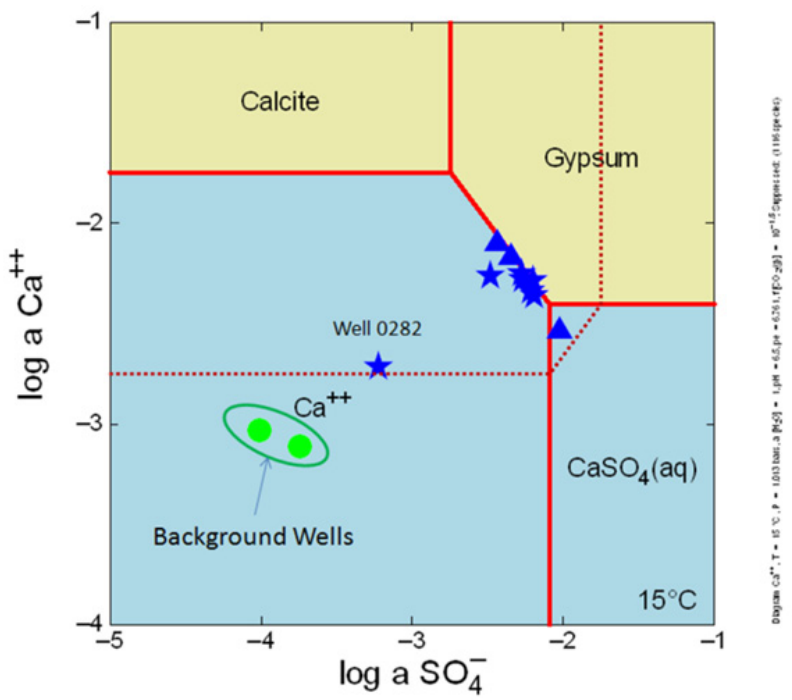

Figure 12: Activity-activity diagram of $\mathrm{Ca}^{+2}$ vs. $\mathrm{SO}_{4}{ }^{-2}$ showing the composition of Tuba City groundwater relative to the stability fields of gypsum and calcite; Horizon A wells (blue triangles), Horizon B wells (blue stars), background wells (green circles); red dotted line shows stability fields under background conditions. 
Precipitation of gypsum within the plume is potentially important to the performance of the treatment system. Poor pumping rates of extraction wells observed at Tuba City within the plume may be due to decreased permeability caused by gypsum precipitation. Even if gypsum replaced calcite there would be a net porosity loss because of the greater molar volume of gypsum $\left(75 \mathrm{~cm}^{3} /\right.$ mole $)$ relative to that of calcite $\left(37 \mathrm{~cm}^{3} /\right.$ mole $)$. The presence of gypsum is also a secondary source of sulfate that will continue to feed the plume until the gypsum is gone.

A secondary source of uranium may also exist in the subsurface near the former tailings pile. Lysimeter data from 1986 show high concentrations of uranium and sulfate in pore waters associated with the tailings pile (DOE, 1998). The maximum sulfate concentration was four times higher than the maximum observed in groundwater a decade later. Yet, the maximum uranium concentration from the lysimeter data was over 50 times the maximum observed in groundwater a decade later. This suggests substantial attenuation of uranium in the unsaturated zone. In addition, the extent of the recent uranium plume (DOE, 2012) and the gradient in concentrations relative to the nitrate plume also suggests some attenuation of uranium.

The degree of attenuation of uranium in the unsaturated zone suggested by the lysimeter data is consistent with precipitation of a uranium phase within the unsaturated zone. This is supported by core analyses reported in DOE (2004) showing that the highest solid phase concentrations of uranium are in the unsaturated zone. Adsorption would not be expected to account for this given the chemistry of the pore waters. This leaves precipitation of uranium-bearing minerals as the probable attenuation mechanism. Identification of the mineral phase or phases can only be done by analysis of cored material. Nevertheless, groundwater data can provide suggestions. Figure 13 shows recent groundwater compositions plotted on stability diagrams of carnotite and soddyite. The carnotite diagram assumes a vanadium concentration of $0.1 \mathrm{mg} / \mathrm{L}$. At this vanadium concentration, the plume groundwater is just undersaturated with carnotite. At the measured silica and uranium concentrations, the plume groundwaters are slightly oversaturated with soddyite. The red dotted line shows the soddyite stability field calculated at conditions representative of the background waters (wells 0901 and 0910). The background waters and water from well 0282 on the fringe of the plume are also very close to saturation with soddyite.
Key Points:

The near-field groundwater is oversaturated with minerals that will precipitate in the formation and in/around extraction wells reducing hydraulic conductivity and impacting the ability to reliably operate

As water is extracted, cleaned and recirculated through the site, dissolution of these minerals will reduce the effectiveness of flushing (e.g., sulfate will be replenished from gypsum that has formed in the aquifer)

Precipitates formed in the capillary fringe may be inundated near the injection trench due to mounding of groundwater. 


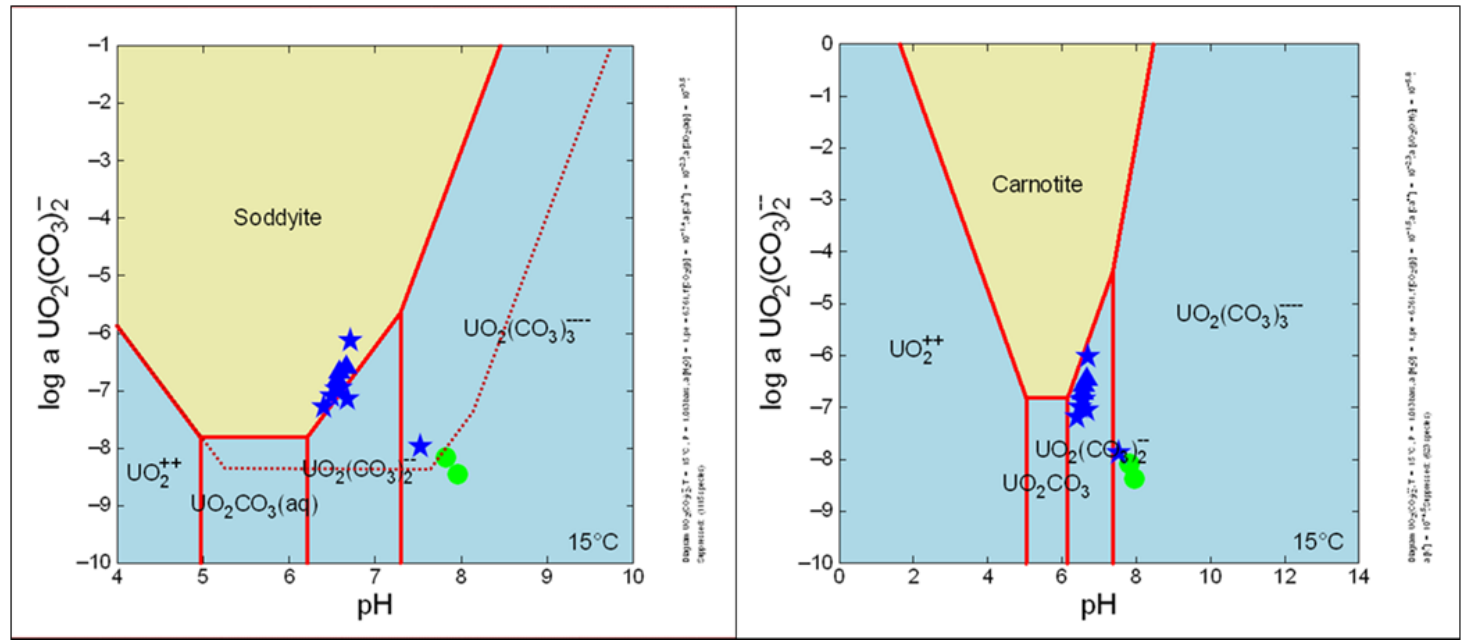

Figure 13: Tuba City groundwater compositions (DOE, 2012) relative to the stability fields of soddyite and carnotite; Horizon A wells (blue triangles), Horizon B wells (blue stars), background wells (green circles); red dotted line shows stability fields under background conditions.

The possibility that a uranium silicate such as soddyite might control uranium concentrations should be considered. Dissolved silica concentrations in samples from all of the wells are elevated, closer to equilibrium with cristobalite than quartz. It is also feasible that beneath the tailings pile the acidic infiltrate preferentially leached aluminum from clay minerals leaving some reactive form of silica. Interaction of uranium-bearing leachate with the silica could have formed uranium silicates.

The observations relative to the geochemical framework at Tuba City may are also pertinent to other LM UMTRCA sites. In particular, the reaction of extreme chemistries of the leachate from uranium milling processes with underlying rocks can significantly influence the nature, behavior, and clean-up of contaminant plumes. Examples from Tuba City are:

- Attenuation of uranium migration by precipitation of uranium-bearing minerals as the extreme chemistry of leachate becomes neutralized

- Plugging of porosity and concomitant decreases in permeability by precipitation of minerals. Gypsum is likely to precipitate at sites that used a sulfuric acid process and have underlying calcareous rocks/sediments. This may contribute to poor extraction well performance at Tuba City.

- Gypsum precipitation provides a lingering source of sulfate that will cause elevated sulfate concentrations in groundwater

- Radium may coprecipitate with calcium in gypsum, removing it from groundwater, but leaving a source of radon

Chemical composition of groundwater can suggest the occurrence of these reactions, but they can only be confirmed by analysis of the rocks/sediments in the reaction zone. 


\section{Recommendations based on the Geochemical Conceptual Framework}

Identification and quantification of near-field uranium attenuation mechanisms requires detailed studies of aquifer solids from the contaminated area, as well as laboratory studies. The magnitude of the attenuation factors may be relatively low but still important when transitioning from an active treatment system to a more passive remediation strategy. The technical assistance team recommends pursuing these studies prior to the shutdown of the $\mathrm{p} \& \mathrm{t}$ system, particularly if modeling under the assumption of no sorption implies remedial standards will be difficult to achieve.
Key Points:

Concentration ratios (e.g., from lysimeter samples to groundwater) suggest that uranium attenuation may be occurring.

Uranium interactions with silica and precipitation may contribute to attenuation

\subsection{Application of Key Tuba City Frameworks: Legacy Management Challenges and Opportunities}

\section{Current Pump and Treat System}

The operation of the groundwater pump and treat ( $\mathrm{p} \& \mathrm{t})$ system at Tuba City is currently the primary focus of on-site activities. The performance and cost of the system have emerged as overriding challenges, both in the near-term and projected into the future. The existing p\&t system comprises 37 extraction wells that produce 100 gpm or about $375 \mathrm{~L} / \mathrm{min}$ (nominal) for treatment using distillation; the distilled water is reinfiltrated into the subsurface using an trench installed on the NW edge of the stabilized tailings and the brine is discharged to a lined pond for evaporation. Implicit in an effective $p \& t$ remedy are the successful operation and efficient performance of the two major subactivities:

1) In the subsurface, extraction of contaminated water and infiltration of clean water, and,

2) Above ground, robust and cost effective water treatment and disposal of secondary wastes. The Tuba City p\&t system faces significant challenges, both in the subsurface and above ground. Beginning with the above ground subcomponent of p\&t, we evaluate some of the key challenges below and provide recommendations.

The objective of the above-ground treatment operations is to separate the contaminated groundwater into two effluent streams. The bulk of the influent volume (approximately $90 \%$ ) is converted to clean water for reinfiltration. The remainder of the volume contains all of the contaminants and other dissolved constituents from the original groundwater along with any chemicals added during treatment. As noted above, this brine is directed to a lined basin for evaporation. 
The on-site management and staff provided a detailed briefing on the existing treatment system including physical examination of all of the major unit operations and equipment. Continuous operation of a large scale distillation system is challenging, and we commend the Tuba City management and staff for their safety and professionalism. Notably, the LM contractor team installed an innovative state-of-practice distillation system (a "falling-film vapor recompression distillation process") to achieve the treatment objectives. Further, the contractor team has incorporated a number of components/actions to optimize the distillation, including: various types of heat recovery, solar heat collection system (installed for use in the future), supplemental solar photovoltaic energy, groundwater pretreatment (softening), and frequent process monitoring to minimize scaling. Use of an innovative distillation process and attention to energy recovery, in particular, have partially mitigated the high energy requirements associated with evaporating large volumes of water. Despite the high quality efforts, the treatment system has significantly underperformed (operating less than $20 \%$ of the time in 2012) and has incurred high operation and maintenance costs. Recent procedural changes and system modifications by the staff at Tuba City have improved distillation system operations - resulting in "several weeks of continuous operations."

Large-scale distillation systems are complex and subject to shut down due to failures in any of the numerous processing steps, scaling or clogging of equipment/heat exchangers/transfer lines, solids build-up on the "falling-film" distillation membranes, leakage of vacuum/vapor or water, scheduled or unscheduled cleaning or maintenance, and other factors. Thus, compared to a number of alternative water treatment methods, large-scale distillation systems are relatively labor intensive and typically are not as robust or reliable. Two notable treatment alternatives are reverse osmosis and spray evaporation.

As an alternative to the distillation system, a properly designed reverse osmosis would provide reasonable performance in terms of separating water into bulk clean effluent (approximately 70 to $75 \%$ of the influent volume) and low-volume contaminated brine (approximately 25 to $30 \%$ of the influent volume). In the last decade, since the original technology selection process for the Tuba City groundwater treatment system, significant improvements have been made to reverse osmosis systems. Such systems are now in widespread use for large-scale continuous water treatment and desalinization. This has led to
Key Points

Continuous operation of a largescale distillation system is challenging and costly.

State-of-practice energy recovery and supplementation modifications in the existing Tuba City distillation system mitigate some of the high energy requirements

More robust treatment technology alternatives, notably reverse osmosis, are available to meet similar performance objectives

If groundwater $\mathrm{p} \& \mathrm{t}$ continues beyond the scheduled life of the distillation system (or a major distillation system component such as the energy recovery membrane), then LM should consider an orderly transition to alternative technology(ies). 
relatively low costs for package systems. Midrange systems to treat 100 to $200 \mathrm{gpm}$ (375 to $750 \mathrm{~L} / \mathrm{min}$ ) are available off-the-shelf from multiple vendors using commodity membranes and components.

While significant work would be needed for careful implementation, a reverse osmosis system can be viewed as a simple one-for-one replacement of the entire distillation operation at Tuba City. At this site, the groundwater is generally amenable to reverse osmosis but would require appropriate pretreatment. Existing Tuba City softening and acidification systems could be used with minimal modification to prepare water for reverse osmosis treatment. It is likely that addition of standard filtration systems and maintenance would be required to control the "silt density index" (a measure of solids content to help assure that the water is suited to reliable reverse osmosis operation). Any required filtration can be integrated into the reverse osmosis design/procurement and would likely consist of a self-cleaning granular filter (minimal maintenance) followed by a pleated cartridge filter (nominal monthly replacement frequency). Periodic membrane cleaning (nominal quarterly to semiannual frequency) would be incorporated into site operations. Onsite membrane cleaning systems are available from vendors as well as equipment for any additional required water conditioning. Modular membrane replacement (nominal 3-5 year frequency) is straightforward.

Figure 14 depicts a high quality single pass commercial reverse osmosis system. Using available high performance and high flow membranes, this system is sized to treat approximately $100 \mathrm{gpm}(375 \mathrm{~L} / \mathrm{min})$. The photograph indicates the approximate physical scale for this reverse osmosis treatment unit including space for membrane element removal and installation. The approximate footprint $\left(<20 \mathrm{~m}^{2}\right.$ floor space plus an adjacent area for a standard packaged filtration system and piping) compares favorably to the existing distillation system. Further, as depicted in the photograph, reverse osmosis represents a significant simplification in equipment that would translate to a commensurate simplification in maintenance and upkeep. Currently available reverse osmosis systems are expected to achieve the required water quality. However, if the water quality in the effluent from reverse osmosis alone does not meet requirements for reinfiltration, standard polishing modules for high volume continuous deionization are available (however, these would result in additional waste brine/reject generation at a rate of about $4 \%$ of the original influent flow). 


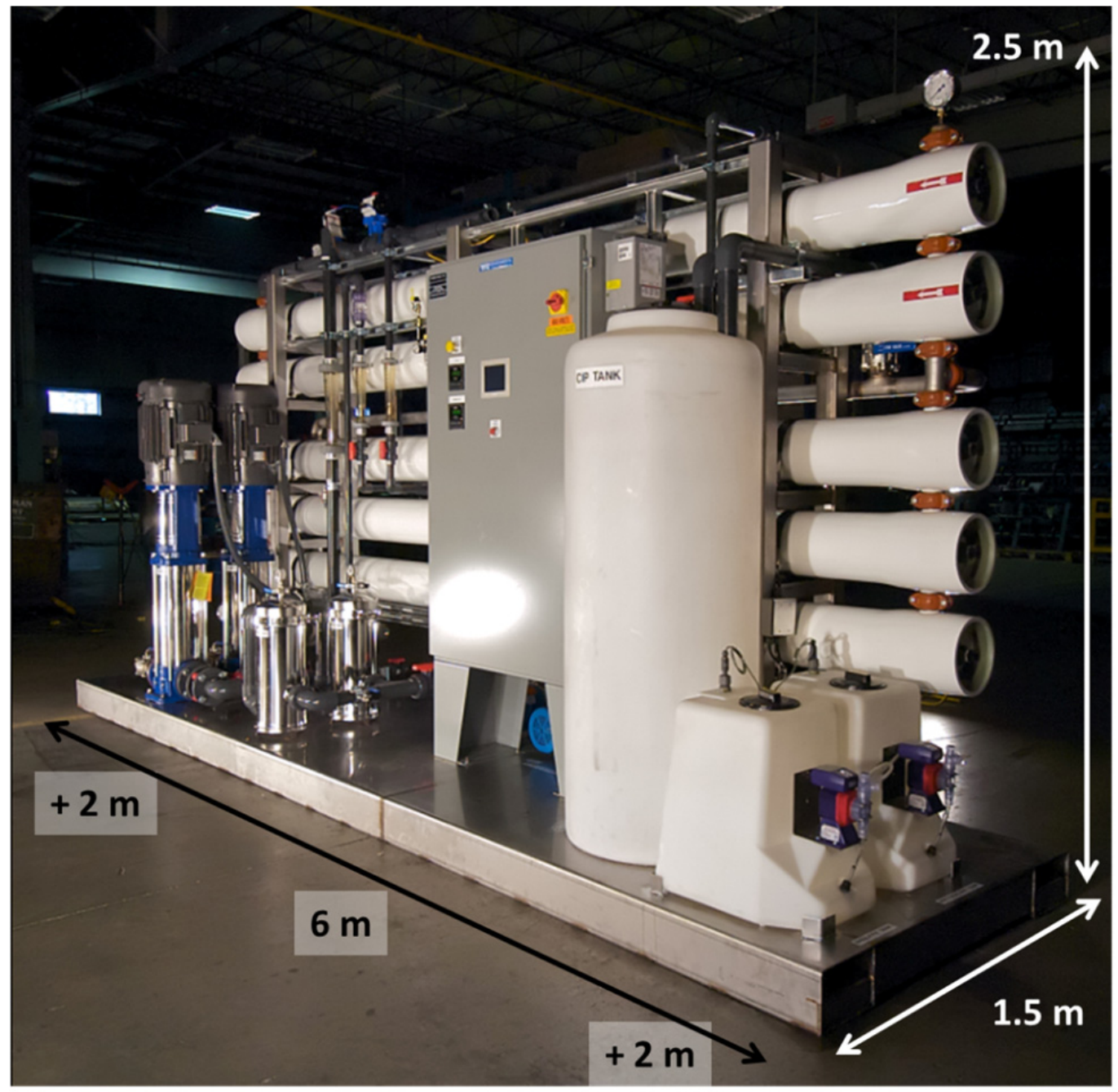

Figure 14. Example of commercially available reverse osmosis system - at an appropriate size needed for Tuba City groundwater treatment.

Industrial scale single pass system (TTX Environmental, Sturgeon Bay WI) 
Spray evaporation, or "Enhanced Evaporation Systems," represent another technology that may be useful at Tuba City. This technology would be used to discharge groundwater and/or waste brine to the lined evaporation pond to maximize the fraction evaporated and to improve overall system performance. Evaporators could be used as a standalone technology (groundwater extraction $\rightarrow$ spray evaporation) or in combination with reverse osmosis. Spray evaporation is a beneficial adjunct to reverse osmosis because it would reduce liquid brine input rates to the evaporation pond (reverse osmosis brine/reject production rates are slightly higher than distillation so this would help assure acceptable evaporation performance with the existing pond footprint). A typical spray evaporation system is depicted in Figure 15. This type of commercial system is designed to minimize scaling and the associated maintenance requirements. Intensive use of spray evaporation would reduce the water available for reinfiltration and result in a higher net system groundwater extraction rate and more significant drawdown. Any collateral impacts of such water level change (both positive and negative) would need to be considered in selecting and sizing this technology.
Key Points

Spray evaporation is a simple and low-cost technology to increase water evaporation.

At arid sites, like Tuba City and many other LM sites, spray evaporation is relatively effective and can disposition significant water flows.

For contaminated water, spray evaporation needs to be carefully implemented to control the potential for spreading by wind.

Limited spray evaporation could be beneficial if used in combination with reverse osmosis to help optimize overall flow capacity
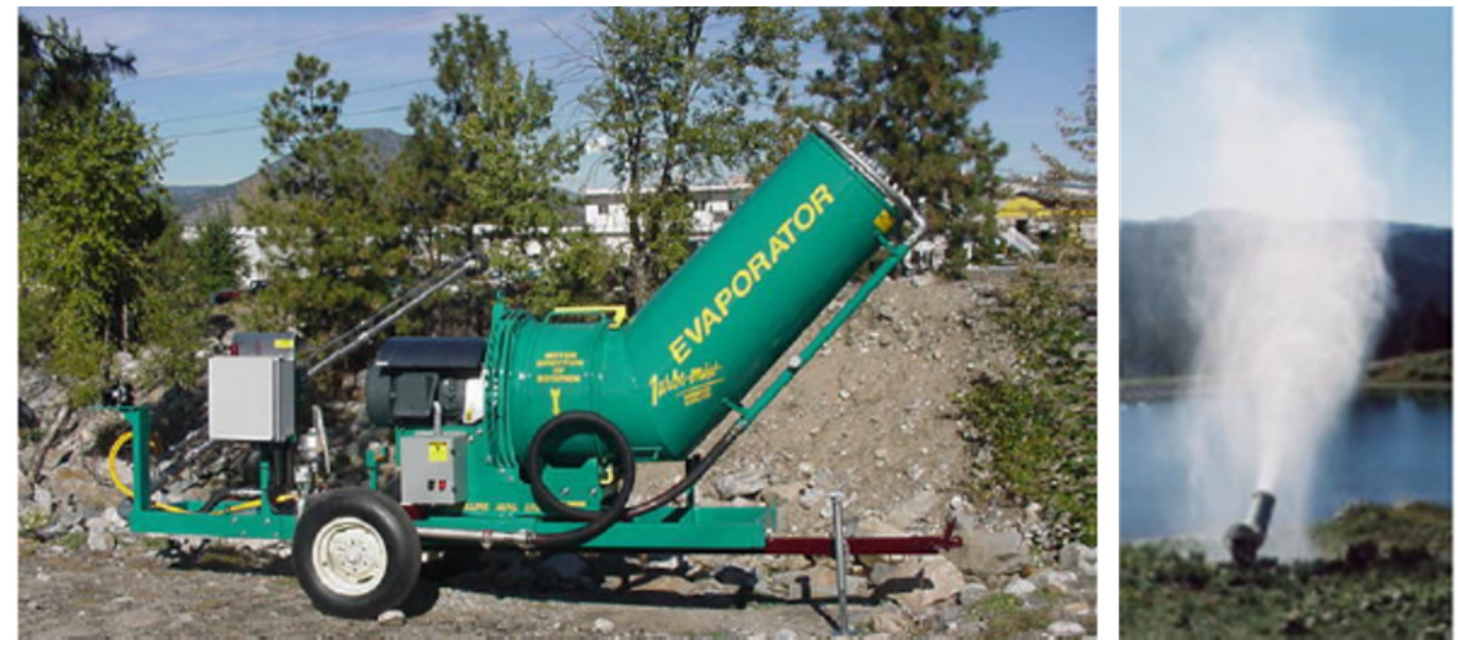

Figure 15. Example of commercially available spray evaporation system Turbo-Mister Enhanced Evaporation System (Slimline Manufacturing, Penticton BC Canada) 
The arid climate in the Tuba City area is conducive to spray evaporation, particularly during the summer. Using standard assumptions, conservative estimates of continuous spray evaporation flow rates from a single evaporator would exceed 10 gpm $(38 \mathrm{~L} / \mathrm{min})$ and summertime flow rates greater than $100 \mathrm{gpm}(375 \mathrm{~L} / \mathrm{min})$ are theoretically feasible for a nominal four acre lined evaporation pond catchment using multiple evaporator units. In general, spray evaporation systems are simple and robust. When used for contaminated water, however, operation of a spray evaporation system would need to be carefully implemented and controlled to minimize any loss or spread of contaminants beyond the evaporation pond boundaries, and minimize exposure of personnel or visitors to contaminants (e.g., by operating during specified wind conditions or times). There are a number of technical references available that would support the development of protocols for safe operation of spray evaporation (e.g., DOE, 2003; Flach, 2002).

A key component of the above-ground activities is the evaporation pond. This pond is accumulating solids that contain groundwater constituents along with any chemicals added as part of the softening and water treatment processes. This solid material will ultimately need to be safely disposed or isolated. If the timeframe for accumulation of the waste is extended (i.e., due to long term p\&t operation), we encourage DOE to reconfirm that the original planned disposition pathways for this solid waste will be available and/or to develop viable alternative strategies.

Effective extraction of groundwater is a crucial step in operating a viable $\mathrm{p} \& \mathrm{t}$ system. Unfortunately, the subsurface portion of the $\mathrm{p} \& \mathrm{t}$ has underperformed in the initial years of system operation. The original design basis focused on extracting $100 \mathrm{gpm}(375 \mathrm{~L} / \mathrm{min}$, increasing to about $200 \mathrm{gpm}(750 \mathrm{~L} / \mathrm{min})$ in a second phase) and effectively flushing one or two "pore volumes" of contaminated groundwater beneath the stabilized tailings. The added driving force of the water from the infiltration trench is intended increase hydraulic gradients and to accelerate the flushing. Field experience has tempered the original objectives. The bulk of the water for treatment is extracted from only a few of the recovery wells and a large number of the wells in the system do not produce significant amounts of water (e.g., $0.1 \mathrm{gpm}$ or less). Over an extended timeframe, the uneven hydraulic performance would correlate with water flow through some areas (i.e., flushing) and not through other areas. Further, the uneven hydraulic performance is a physical manifestation of the heterogeneity described in the temporal framework - active flow paths will clean up relatively rapidly while less active flow paths will clean up slowly and result in tailing and the need for many pore volumes to achieve remedial objectives throughout the groundwater.
Key Points

The remediation wells at Tuba City are not effectively extracting the contaminated groundwater - many of the wells produce less than $0.1 \mathrm{gpm}$

In the contaminated plume at Tuba City a number of geochemical processes (such as gypsum precipitation) would result in reduced hydraulic conductivity and difficulties in effectively operating extraction wells

Low flow and mineral dissolution extend the timeframe for remediation 
There are a number of factors that contribute to low flow and the challenge of operating a network of extraction wells in this particular contaminated plume. As described in the geochemistry framework, significant portions of the plume are subject to precipitation of gypsum, calcite or silicates. In those areas, the solids formed would reduce hydraulic conductivity and contribute to scaling on wells screens and pumps. Any solids formed in the formation would be subject to future dissolution, re-contaminating clean water as it flushes through the system. For some of the target contaminants, such as sulfate, the aquifer currently contains a large quantity of source solid that would extend the remediation timeframe "indefinitely" (i.e., until the precipitated minerals are dissolved and removed). The timeframe for other contaminants, such as uranium, may also be extended since these elements are often incorporated in/on gypsum, calcite and silicates. Significantly, the portions of the plume that have been impacted by the highest levels of contamination would have been subject to highest levels of solids precipitation and would be the most important to flush. But these areas would produce less water while requiring many more flushing volumes to achieve remedial goals. This discordance between fundamental natural controls/processes in the subsurface and remediation performance needs is a significant and overriding challenge.

Elements of the hydraulic framework are also relevant to the assessment of past and future performance of the groundwater extraction and reinjection system. For example, the water table will mound near the injection trench due to the localized water input and the general water table in the plume zone will decrease (because a fraction of the water is being removed and diverted to the evaporation pond). Water table mounding will inundate potentially contaminated deep vadose zone sediments resulting in possible recontamination. Similarly, after an extended period of groundwater $\mathrm{p} \& \mathrm{t}$, the rebound of water table will bring groundwater in contact with contaminated sediments upon shut down resulting in increased contaminant concentrations. When extended to the entire flow path, the lowering of the water table may impact the important downgradient natural attenuation processes (by moving the water table farther from the land surface and decreasing access by phreatophyte plants). This suppression of the systems natural attenuation mechanisms is a potential negative impact of operating the $\mathrm{p} \& \mathrm{t}$ system. Further, if this natural attenuation suppression is occurring, then any p\&t system modification that would result in a reducing the fraction of pumped water available for reinjection, such as reverse osmosis and spray evaporation, Key Points Groundwater level fluctuations may impact contaminant concentrations.

Net water removal by the $\mathrm{p} \& \mathrm{t}$ system (i.e., the water sent to the evaporation basin) will lower water levels and may reduce the effectiveness of downgradient natural attenuation mechanisms would result in the collateral impact. 
In summary:

- The p\&t system will require an extended timeframe to achieve remediation objectives; if p\&t is determined to be necessary, many decades of operation would be needed

- If $\mathrm{p} \& \mathrm{t}$ is continued for an extended timeframe, DOE should initiate an orderly process to transition the above ground treatment technology to a more costeffective robust technology such as reverse osmosis and spray evaporation

- Reliable installation and continuous operation of recovery wells represent an ongoing challenge; a program of well replacement/relocation/rework will be needed if long term operations are required

- The issues and challenges associated with all aspects of the p\&t system, both above ground and in the subsurface, increase the urgency and potential significance of efforts to document natural attenuation processes occurring along the flow path

Characterization and Monitoring of the Evaporation Discharge Boundary

A key recommended refinement of the conceptual site model is to confirm and incorporate the evapotranspiration discharge boundary zone in developing site strategies. A focused characterization study of the critical transition region from the middle and lower terrace and the lower terrace to the Greasewood area would support both conceptual model development and provide a strong technical basis for productive stakeholder and regulatory interactions. As noted above the conceptual model of such boundaries results in relatively clear geochemical signatures and distributions. In some cases, the required characterization would be straightforward, such as surveying the area for surficial mineral signatures associated with seeps. Such a study would utilize easily collected samples and rapid-low cost screening equipment or test kits. In these cases, identification of a local partner and collaboration educational institutions (high schools or universities) might be possible as a mechanism for surveying the area. Characterization of the depth profiles in the vadose zone (in both plume areas and nearby background areas) is also recommended to determine the presence and nature of non-pedogenic minerals above the water table. In this case, analysis of depth discrete sediment and water samples would be used (Figure 16).

In the evaporative boundary characterization activities, we recommend mapping the distribution of key physical parameters such as soil lithology and moisture, chemical parameters such as $\mathrm{pH}$, specific conductivity, sulfate, nitrate, and key elements, and mineralogical composition. Densely space measurements with inexpensive techniques could be made to refine the conceptual model with confirmation using more expensive methods. 


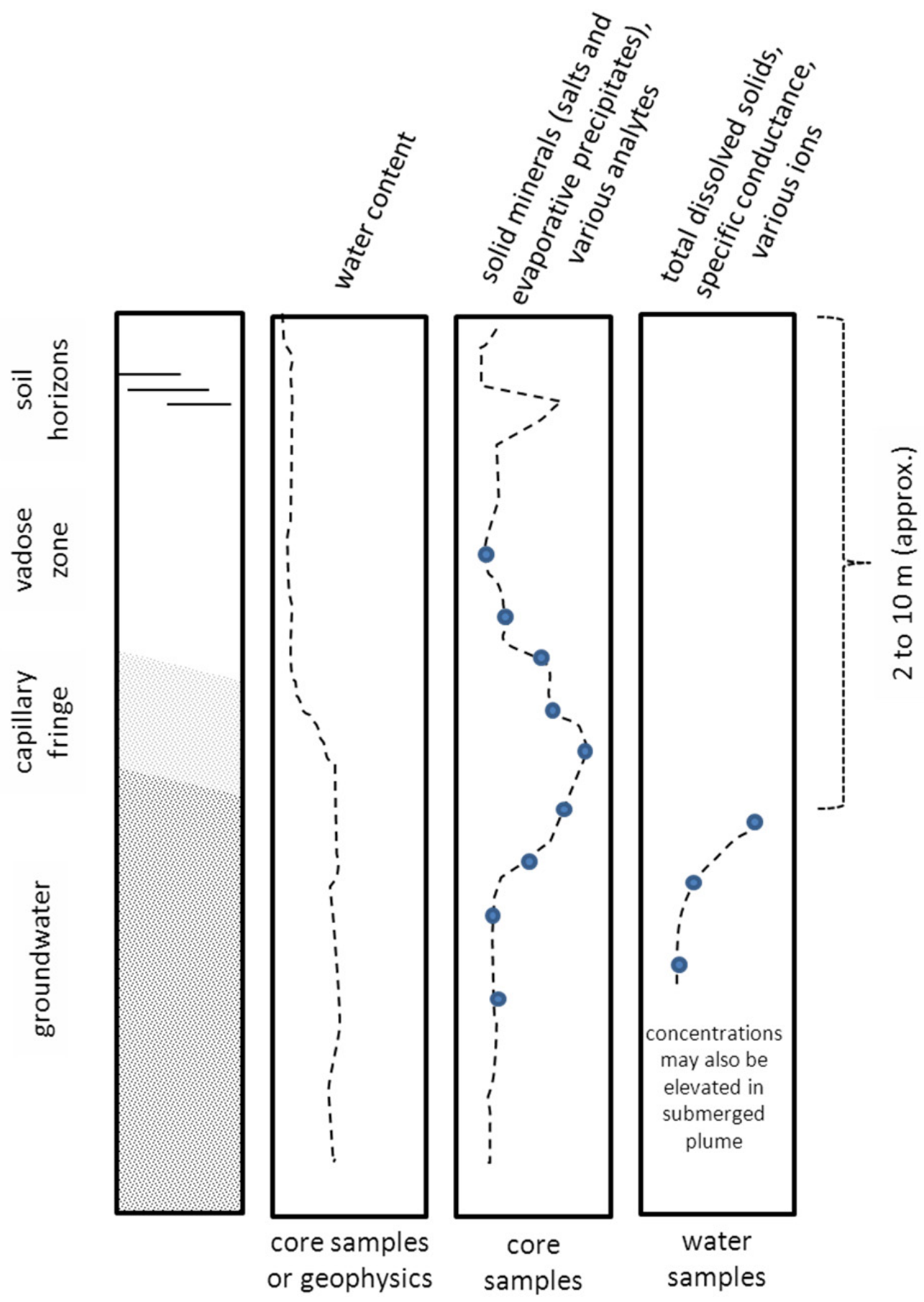

Figure 16. Hypothetical behavior of depth profiles that would help confirm and quantify the evaporative discharge boundary

Table 1 summarizes some of the options for the recommended characterization. Note that these are not proscriptive and a comprehensive application of all of the listed methods is not necessary, however, sufficient data and multiple lines of evidence should be considered in the study design and in developing the data quality objectives. 


\begin{tabular}{|c|c|c|}
\hline & Method & Comments \\
\hline \multirow[t]{6}{*}{ Surface Sampling Methods } & Grab Samples & \\
\hline & $\begin{array}{l}\text { Shallow Hand } \\
\text { Driven Cores }\end{array}$ & \\
\hline & TDR probes & $\begin{array}{l}\text { In-situ measurement of Moisture } \\
\text { Content }\end{array}$ \\
\hline & Field XRF & $\begin{array}{l}\text { Identification of solid phase } \mathrm{Ca} \\
\text { and } \mathrm{U} \text { associated with } \\
\text { precipitated minerals }\end{array}$ \\
\hline & $\begin{array}{l}\text { Aerial gamma } \\
\text { survey }\end{array}$ & $\begin{array}{l}\text { Identification of seep areas and } \\
\text { precipitated surface minerals }\end{array}$ \\
\hline & $\begin{array}{l}\text { Walkover/drive- } \\
\text { over gamma } \\
\text { survey }\end{array}$ & $\begin{array}{l}\text { Identification of seep areas and } \\
\text { precipitated surface minerals }\end{array}$ \\
\hline \multirow[t]{2}{*}{$\begin{array}{c}\text { Contaminant Analysis-- } \\
\text { Field }\end{array}$} & Agricultural Kits & $\begin{array}{l}\text { Inexpensive field identification of } \\
\text { sulfate and nitrate using simple } \\
\text { shake tests }\end{array}$ \\
\hline & $\mathrm{XRF}$ & $\begin{array}{l}\text { Solid phase } \mathrm{Ca} \text { and } \mathrm{U} \text { associated } \\
\text { with precipitated minerals }\end{array}$ \\
\hline $\begin{array}{l}\text { Mineralogical/Chemical } \\
\text { Identification-- Laboratory }\end{array}$ & $\begin{array}{l}\text { XRF, } \\
\text { SEM/EXAFS, } \\
\text { Thin Section }\end{array}$ & $\begin{array}{l}\text { Laboratory characterization of } \\
\text { sample mineralogy and chemistry }\end{array}$ \\
\hline \multirow[t]{3}{*}{ Borehole Sampling } & $\begin{array}{l}\text { Direct Push Coring } \\
\text { System }\end{array}$ & Preferred \\
\hline & $\begin{array}{l}\text { Hollow stem auger } \\
\text { (split spoon) }\end{array}$ & \\
\hline & RotoSonic & $\begin{array}{l}\text { Carefully consider impacts of } \\
\text { drilling water }\end{array}$ \\
\hline Borehole Logging & $\begin{array}{l}\text { Geophysical } \\
\text { Methods }\end{array}$ & $\begin{array}{l}\text { Gamma logs, neutron logs and } \\
\text { resistivity logs to delineate } \\
\text { mineral accumulation zones } \\
\text { containing gypsum and accessory } \\
\text { radionuclides }\end{array}$ \\
\hline
\end{tabular}

Table 1. Methods for Characterization of the Evaporative Boundary Zone 


\section{Case Study - Use of Existing Aerial Gamma Data to Confirm and Refine the Hydrologic and Geochemical Conceptual Model}

A summary interpretation of existing aerial gamma data provides an illustrative case study of the application of one of the recommended characterization methods. In this case, aerial gamma data have been collected as part of: a) past "North American" surveys of uranium resources, and b) local surveys of uranium mining and milling areas throughout the Navajo Nation. The North American surveys, performed as part of the NURE (National Uranium Resource Evaluation) Program, provide intermediate resolution data and mapping of a number of parameters, including estimated terrestrial gamma dose (at $1 \mathrm{~m}$ above ground), uranium concentration in surficial soils (based on ${ }^{214} \mathrm{Bi}$ ), thorium concentration in surficial soils (based on ${ }^{208} \mathrm{Tl}$ ), and potassium concentration in surficial soils (based on ${ }^{40} \mathrm{~K}$ ). The NURE data are archived by the U.S. Geological Survey (USGS) and are publically available (see Phillips et al., 1993, for details). The North American map is based on approximately 100 million data points. Flight-line spacing ranged from $1 \mathrm{~km}$ to $25 \mathrm{~km}$ - this spacing determines the percentage of a survey block that is sampled with coverages ranging from $1 \%$ to $25 \%$ of the land surface. Thus, the NURE data provide useful regional and national context to relate terrestrial radiation to geologic provinces and predominant surficial materials. However, the NURE data generally do not have sufficient resolution to provide detailed site specific information related to local conceptual models of hydrology and geochemistry.

Of particular interest and value to the site-specific Tuba City evaluation are the high resolution local aerial gamma surveys overseen by Region 9 of the U.S. Environmental Protection Agency (EPA) and described in more detail below. Aerial radiation surveys were flown over 41 blocks in the Navajo Nation during October 1994 through October 1999, and covered areas of known or suspected uranium mining and milling operations, including Tuba City. The surveys were conducted by the DOE Remote Sensing Laboratory to assist with locating and characterizing abandoned uranium mines (AUMs) and to quantify the potential radiation exposures associated with these and other historical uranium mining/milling activities. The surveys were flown using a helicopter-based acquisition platform (see EPA, 2007, for details). These local surveys are particularly useful because they were flown at low altitude ( $45 \mathrm{~m}$ above the terrain) with $\cong 100 \%$ coverage and provide high resolution information. The data were integrated at one second intervals and provide an average radiation level for each $90 \mathrm{~m}$ diameter footprint under the helicopter as shown.

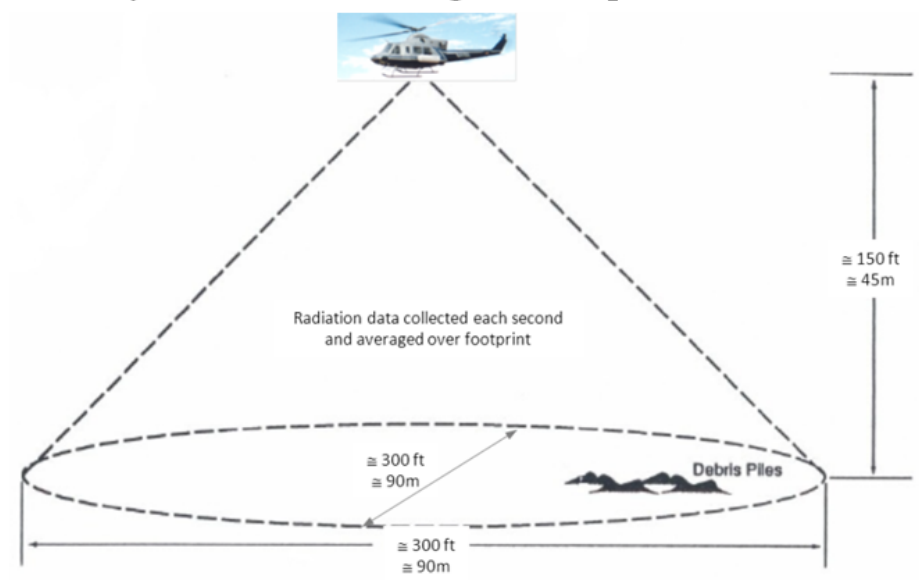


The following narrative provides a synopsis of the relevant aerial gamma data to exemplify how this type of data can be used as a line of evidence to examine site specific conceptual models of contaminant migration.

At a national scale, the NURE data (Figure 17A) indicate background terrestrial gamma exposure levels associated with natural $\mathrm{U}$, Th and $\mathrm{K}$ in surficial soils range from approximately 1 to $15 \mu \mathrm{R} /$ hour (note that the units for all of the maps in this case study have been converted to micro-Roentgen $(\mu \mathrm{R})$ per hour for ease of comparison $-\mu \mathrm{R} /$ hour can be related to effective dose - rem or Sieverts - using standard assumption for gamma radiation). The pattern of terrestrial gamma exposure throughout the US is related to the regional geology and morphology with the higher exposures areas where rocks/soils containing $\mathrm{U} / \mathrm{Th} / \mathrm{K}$ minerals are present near the ground surface and lower exposures in areas such as the weathered Southeastern Coastal Plain. The highest exposures are in the western and southwestern US. The NURE data for New Mexico (Figure 17B) range from 2 to $15 \mu \mathrm{R} /$ hour and the median value tends toward the higher end of the national range with a median terrestrial gamma exposure in the range of 7 to $8 \mu \mathrm{R}$ hour. In the subregional $\left(7000 \mathrm{~km}^{2}\right)$ area surrounding the former Tuba City Mill site (Figure 17C) background terrestrial gamma exposure ranges from approximately 2 to $15 \mu \mathrm{R} /$ hour and in the general vicinity of the site $\left(100 \mathrm{~km}^{2}\right)$ terrestrial gamma exposure ranges from about 4 to $7 \mu \mathrm{R} /$ hour. Figure $17 \mathrm{C}$ demonstrates the resolution limits of the NURE North American dataset and impacts of extrapolation between flight-lines - the map suggests localized gamma signature differences associated with major geomorphological features (e.g., Moenkopi Wash) but local details are smoothed out and are not clearly discernible in the map.

The high resolution data collected for the EPA (Figure 18) provides a significantly clearer picture of the local terrestrial gamma exposure rates/patterns. The overflights for these datasets were performed after 1990; therefore, remediation of localized surface contamination on/near the site was complete and the tailings were consolidated and covered at the time of the high resolution data collection. Figure 18 has been annotated to denote the relationship of the color scale to the North American NURE maps and to designate the approximate regulatory guidelines. Note that all of the data on the local high resolution terrestrial gamma exposure map are within the background data range from the North American NURE data and all of the data are below UMTRCA soil guidelines (e.g., 40CRF192) and unrestricted public access guidelines from NRC and international organizations (e.g., $1 \mathrm{mSv} / \mathrm{yr}$ as designated in 10CFR20 and Health Canada, 2000).

Despite the low levels of radioactivity, the pattern of gamma exposure levels provides a significant amount of information about background conditions and about the potential transport pathways for milling related radionuclides in the vicinity of the Tuba City site. One of the most notable features in Figure 18 is the band of high natural gamma exposures along the entire surveyed reach of Moenkopi wash. This gamma is associated with the evaporative accumulation of minerals in a regional discharge area and the accumulation of heavy minerals due to physical sorting and concentration in a surface water environment that is subject to flash flooding. The background gamma exposure 
levels are the lowest in areas of surficial sand dunes and relatively higher in other areas. In the vicinity of the mill site, there are detectable gamma signatures toward the east, north and south. The eastern gamma signature was previously observed (Havens and Dean, 1967) and attributed to windblown dust from the mill site during the period when the tailings were not consolidated and covered. The north signature is associated with the "Highway 160 Project Site" - an area that was later characterized and cleaned-up (see NNEPA, 2011). The gamma exposure levels are notably low over the area of the tailings cell. Importantly, the data indicate that the LM cleanup actions - collection/consolidation and covering of contaminated tailings and soils - were relatively effective since the terrestrial gamma exposure levels measured in the post-1990 aerial gamma were significantly below the historical values measured by Havens and Dean (1967) and, as noted above, meet applicable guidelines to protect humans and the environment. The gamma signature to the south of the mill site is particularly interesting because it is indicative of groundwater transport and discharge (either at seeps or evapotranspiration boundaries) and/or indicative of erosion and overland transport of contaminated soils from the middle terrace to the lower terrace. The southern transport pathway is limited in scale and is consistent with the expected short flow distances for the uppermost groundwater flow lines or limited erosion. Note that there is no southern transport pathway observed for the windblown area (the surficial contaminants to the east) possible evidence that supports the subsurface/groundwater pathway from the main mill site area. For the southern transport direction, however, the aerial gamma surveys alone do not allow the alternative pathways to be differentiated and additional lines of evidence (e.g., study of contaminant profiles above the water table) would be needed to further refine and quantify the conceptual model.

Note that the overall gamma exposure information can be supplemented and expanded by evaluating specific gamma energies that are related to different potential radionuclide source materials $-{ }^{214} \mathrm{Bi}$ is typically related to terrestrial uranium and radium concentrations. The high resolution map for ${ }^{214} \mathrm{Bi}$ is shown in Figure 19. The distribution in this figure is consistent with the interpretation presented above. Uranium contributes significantly to the gamma exposures near the milling site (to the east and south). There are no significant ${ }^{214} \mathrm{Bi}$ signatures along Moenkopi Wash suggesting somewhat greater relative contributions from potassium and thorium minerals to the overall gamma exposure in this area.

In summary, the aerial gamma data provide a powerful and cost effective technique to test and explore conceptual models of radionuclide transport near the Tuba City Site. Figure 20 depicts the two identified transport vectors: a) wind (toward the east) and b) groundwater and/or overland transport to the south. In this case, existing baseline (NURE) and high resolution (EPA) data were available and easily accessible for mapping and interpretation. This short case study provides a synopsis of how this type of "free" information might be cost-effectively used in combination with some of the other tabulated characterization and monitoring techniques to improve technical understanding of the site, facilitate clear communications with regulatory agencies and the Navajo and Hopi Nations, and inform future environmental management decisions at Tuba City and at other LM sites. 


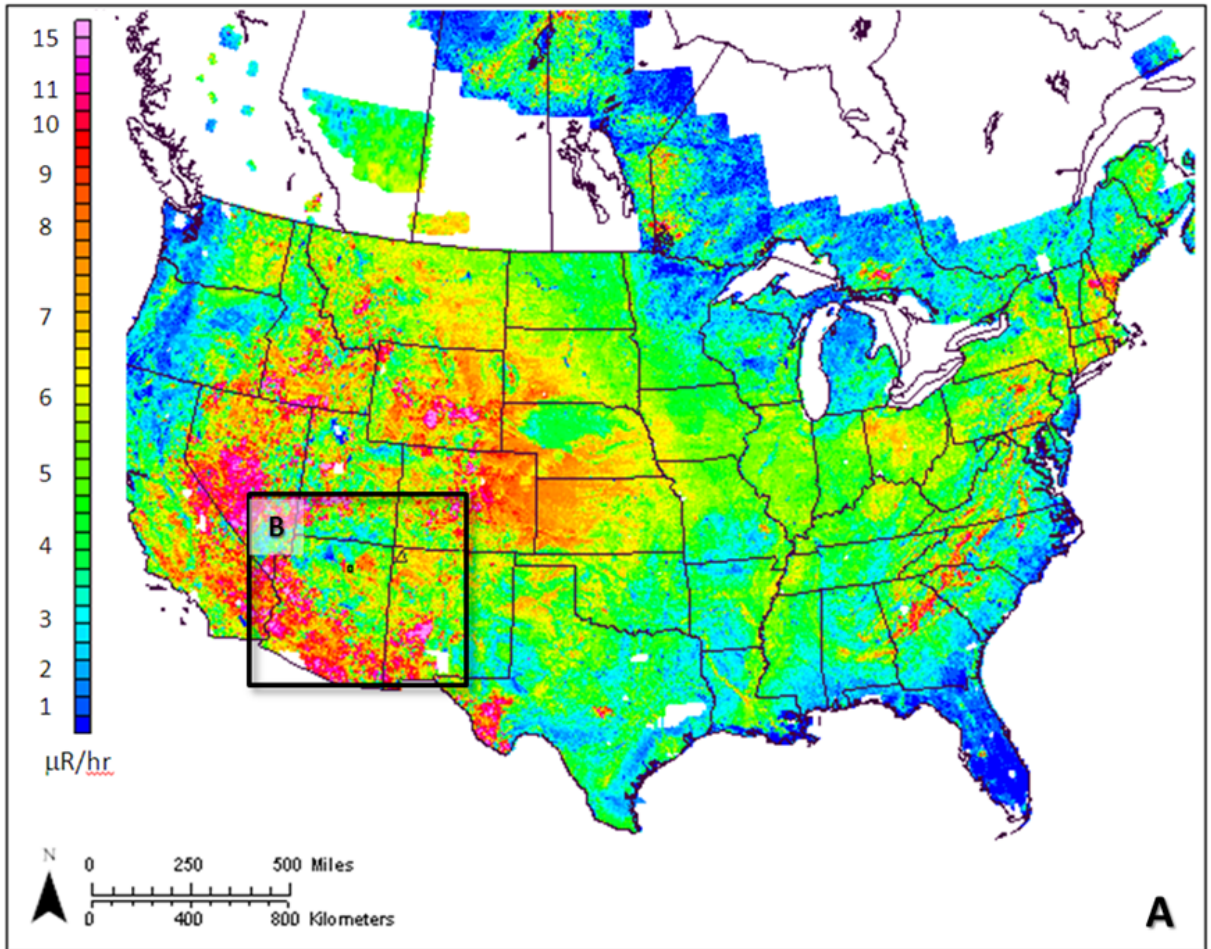

Figure 17A Terrestrial gamma exposure map (uR/hr) based on North America NURE Dataset

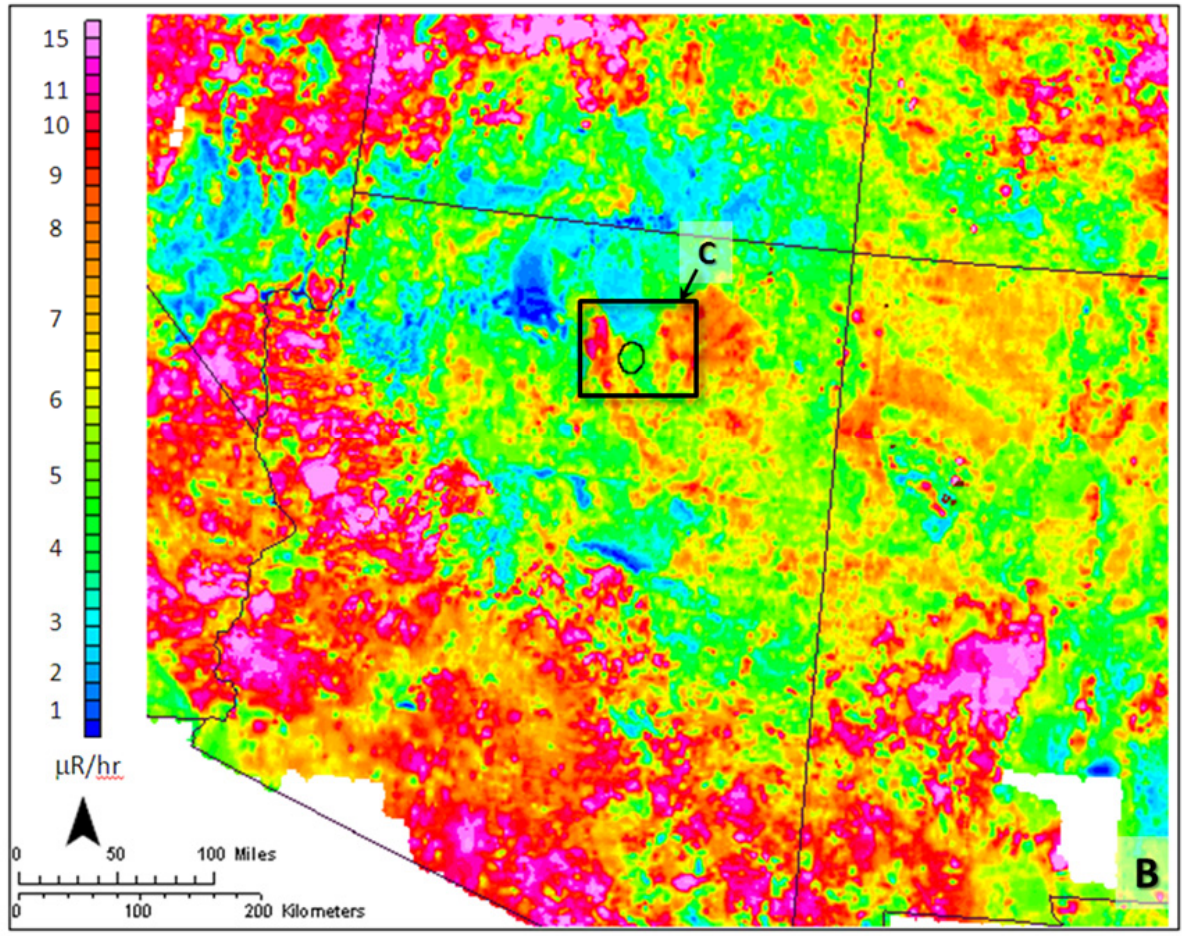

Figure 17B Terrestrial gamma exposure map ( $\mathrm{uR} / \mathrm{hr})$ from NURE dataset for New Mexico Area 


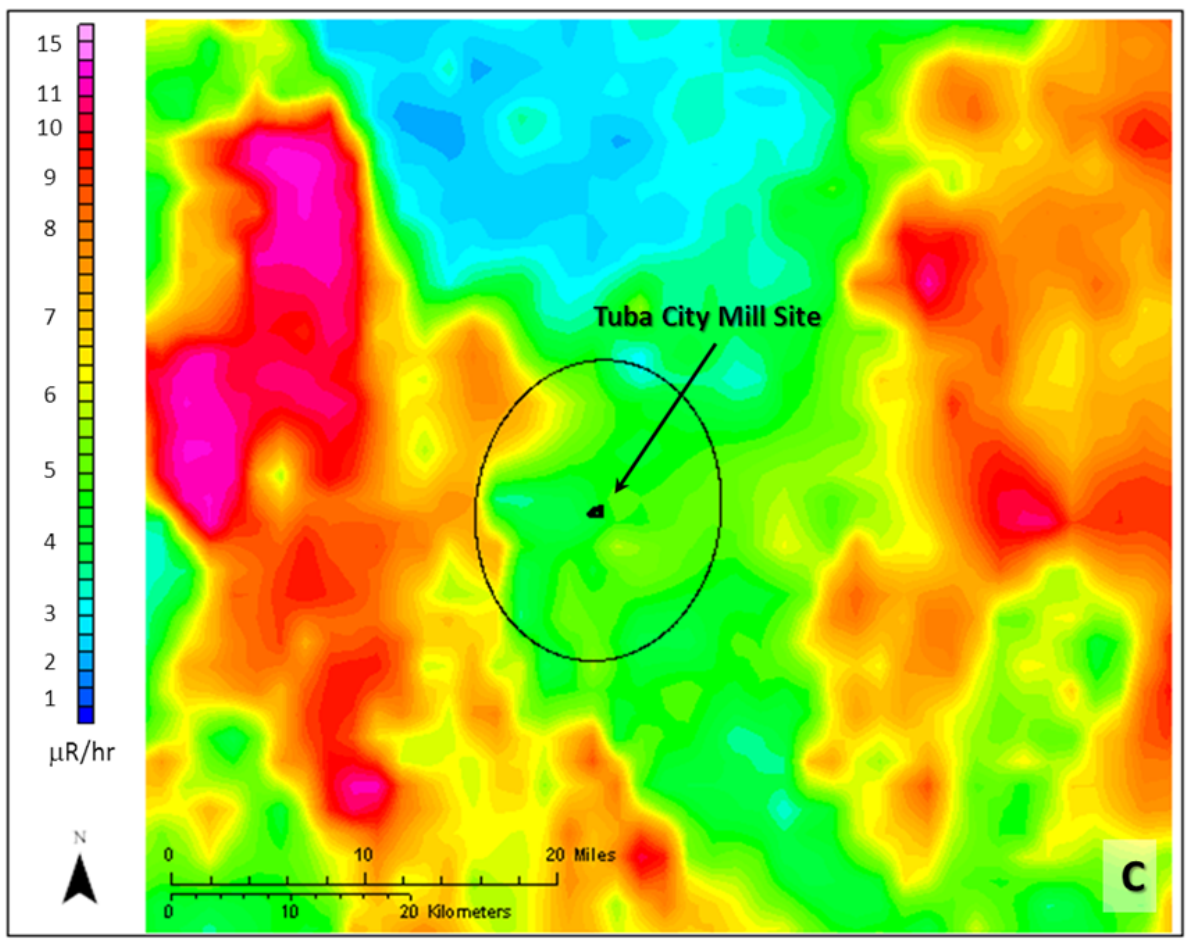

Figure 17C Terrestrial gamma exposure map (uR/hr) from NURE dataset for the area around the Tuba City Mill Site (denoted by the small polygon in the oval) 


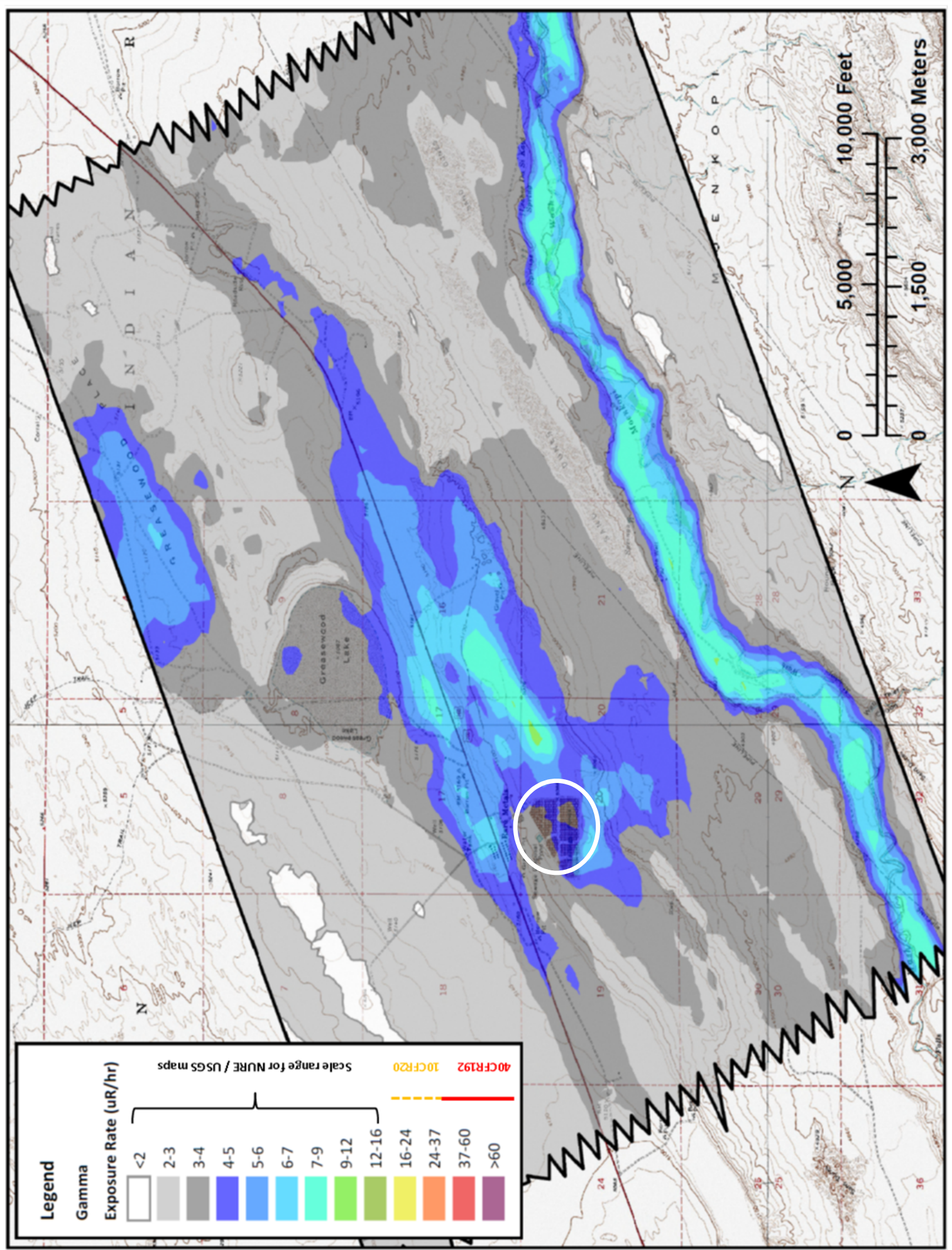

Figure 18. High resolution terrestrial gamma exposure map $(\mathrm{uR} / \mathrm{hr})$ in the vicinity of the Tuba City Mill Site (circled) 


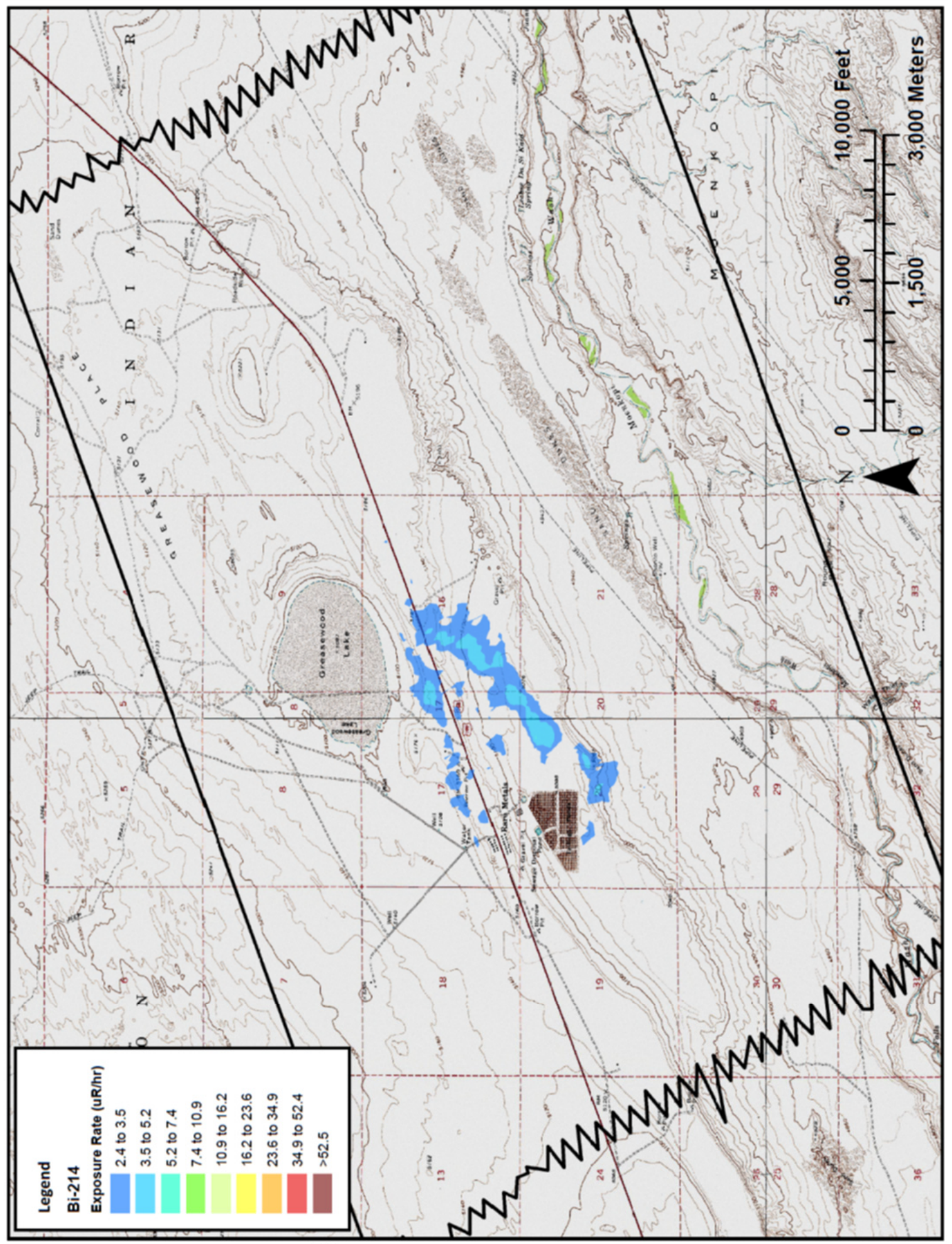

Figure 19. High resolution ${ }^{214} \mathrm{Bi}$ exposure map $(\mathrm{uR} / \mathrm{hr})$ in the vicinity of the Tuba City Mill Site - note that green areas along Moenkopi Wash are depictions on the USGS base map and do not represent gamma exposures 

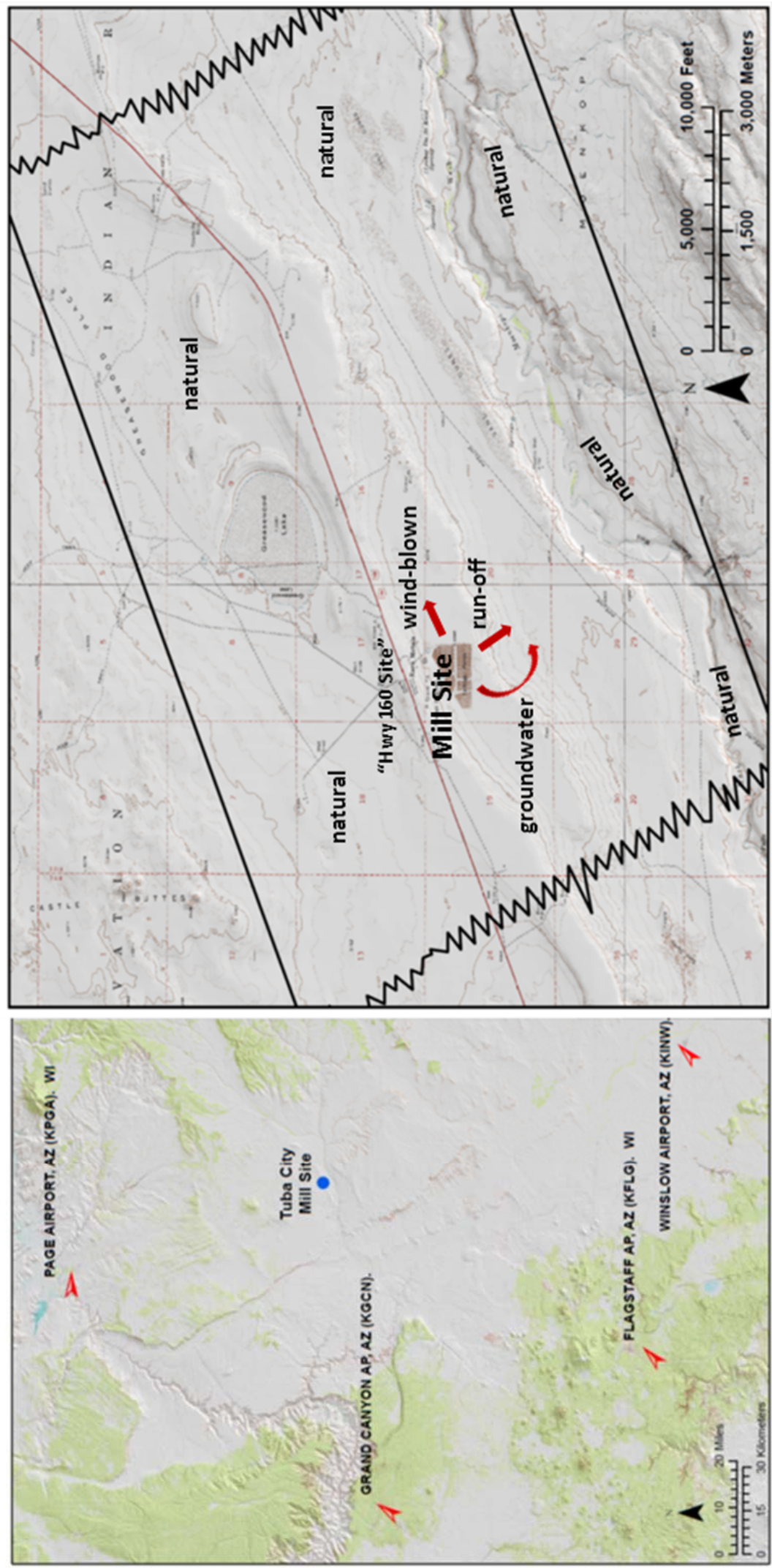

Figure 20. Predominant wind direction and summary of transport vectors in the vicinity of the Tuba City Mill Site 


\section{Long Term Strategy Development}

Developing a safe, viable and productive long-term future use (end-state) for the Tuba City Site is an important component in strategic planning. At many LM sites, the land and facilities are transferred to the local community for transition to beneficial reuse and development. For example, at the former Mound Site, the "brownfield" land and facilities have been transitioned to a local public private partnership, the Mound Development Corporation, that operates the successful Mound Advanced Technology Center. The Mound Site transfer to beneficial reuse took many years and involved a careful-stepwise multi-party process to assure the safety of the new site occupants and the surrounding community. The results of the significant effort, however, have been positive for both DOE and the community. Currently, the Mound Advanced Technology center houses 11 businesses with 256 employees that perform research, development, testing and production of high-tech products and processes.

At the uranium milling and processing site in Gunnison Colorado, LM is in the process of transitioning the land to beneficial reuse in collaboration with the local county government and state/federal regulators. The details of the transfer process are potentially relevant to Tuba City. At the Gunnison Processing Site, institutional controls for future land use were developed with public participation. According to the LM fact sheet:

\footnotetext{
Numerous meetings with citizens and representatives of the city and county were held to provide information and discuss the extent of institutional controls. At Gunnison, "institutional control within the former processing site boundary consists of a restriction that was placed in the deed when the former mill site was conveyed by quitclaim deed from the State of Colorado to Gunnison County. The County agreed not to use groundwater from the site for any purpose and not to construct wells or any means of exposing groundwater at the surface unless it receives prior written approval from the Colorado Department of Public Health and Environment (CDPHE) and DOE. In addition, the County agreed to obtain approval from CDPHE and DOE prior to any excavation or construction activities on the former mill site to ensure that there is no exposure to subsurface contamination. Because uranium contamination in the groundwater extends beyond the former processing site boundary, offsite institutional control was also necessary. In November 2004, the county approved a resolution establishing the New Domestic Well Constraint Area. The purpose of the resolution was to ensure that contaminated water is not made available for domestic use. The resolution prohibits installation of new wells within the institutional control boundary. A water treatment plant, storage tank, and distribution system were partially funded by DOE and installed in 1994 to supply drinking water to all residences within the constraint area boundary..."
}

As discussed below, the Tuba City Site appears to be a good candidate for reuse and represents a potentially significant resource for future employment of local citizens and ongoing benefit to the Native American Nations. A schematic of the steps for such a process is depicted in Figure 21.

The initial stage of the effort would be formulation of a shared vision for redevelopment with the local community and regulators. As shown, the redevelopment process is contingent on confirming that onsite risks are low and that they can be controlled. Further, redevelopment would be contingent on confirming the conceptual models from the hydrologic and geochemical frameworks - specifically the natural ability of the Tuba 
City system to attenuate and limit the extent of the plume and low offsite risks. If these contingencies are met, then the site can be prepared for the transfer by discontinuing pump and treat and transitioning the groundwater strategy to monitored natural attenuation, removing infrastructure that would not be transferred, and general clean-up (e.g., removing/isolating the solids collected in the evaporation pond). Some of the onsite infrastructure would be highly desirable to a potential redevelopment candidate, particularly the large photovoltaic power array, the solar heat collection system and the buildings. It is likely that the availability of such resources would increase the competition for candidate tenants. Based on scale of the Tuba City, it is feasible that one or more small businesses could occupy the site and perform small-scale green manufacturing with the potential to employ a significant number of local citizens.

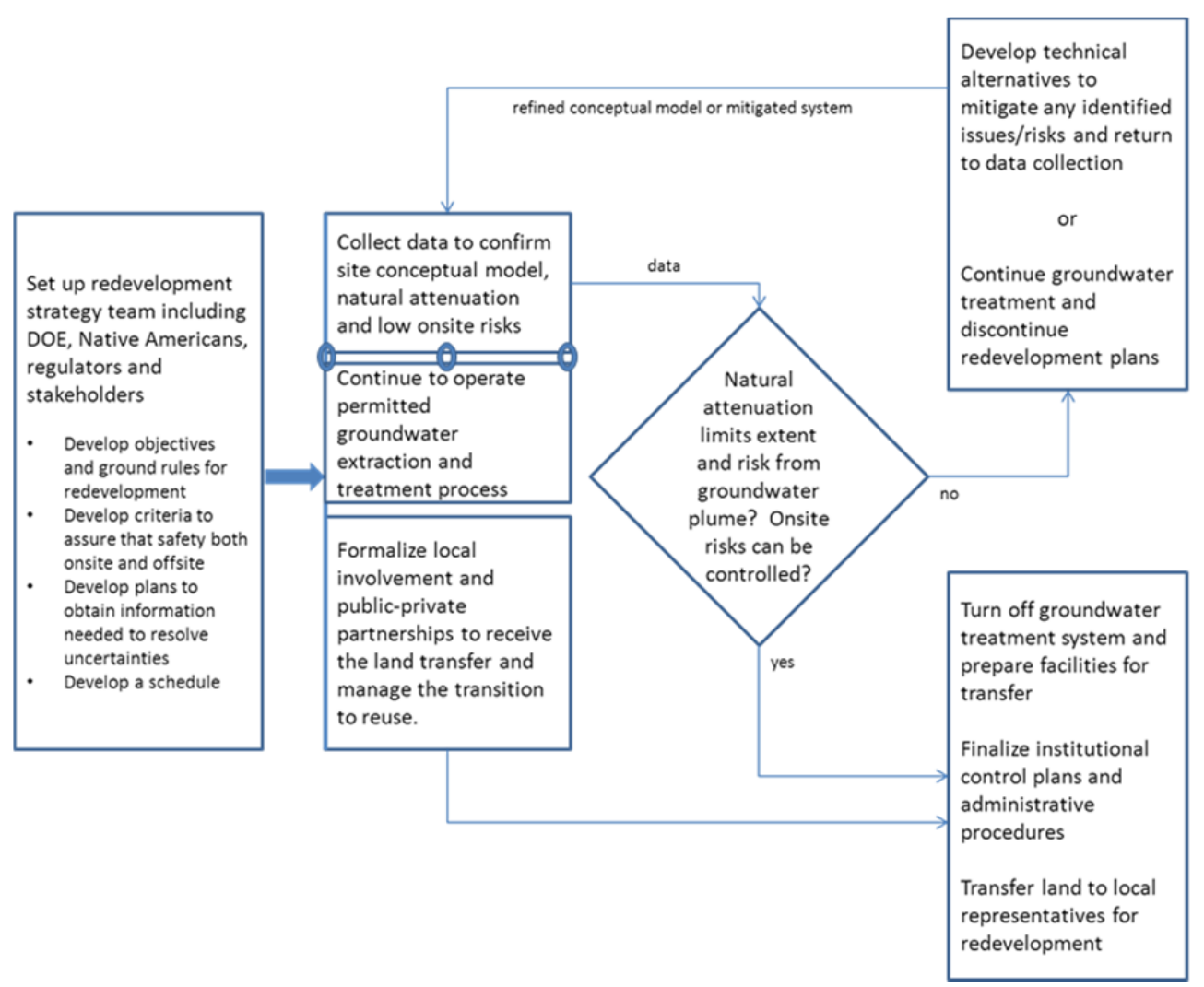

Figure 21. Summary of a process to transition the Tuba City Site to beneficial reuse 


\subsection{Site Specific Observations and Recommendations - Gunnison Processing and Disposal Site}

The Gunnison Colorado Processing and Disposal Sites resulted from the historical uranium-ore-processing operations on a 61.5-acre tract of land adjacent to the Gunnison County airport (Figure 22) and the tailings cleanup/transfer/stabilization in a nearby disposal cell (Figure 23).

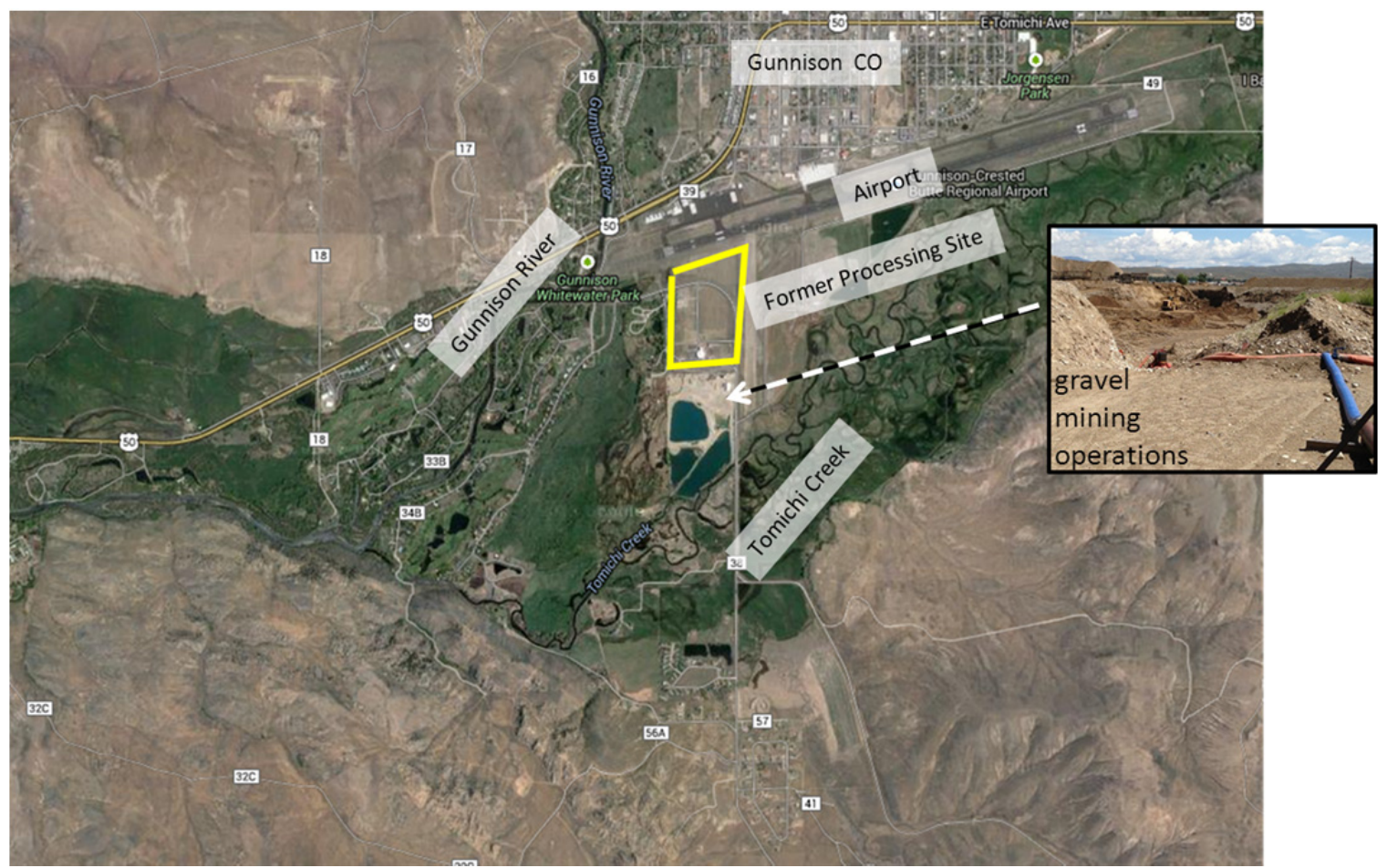

Figure 22. Gunnison Processing Site: Former uranium milling and processing area near Gunnison Colorado
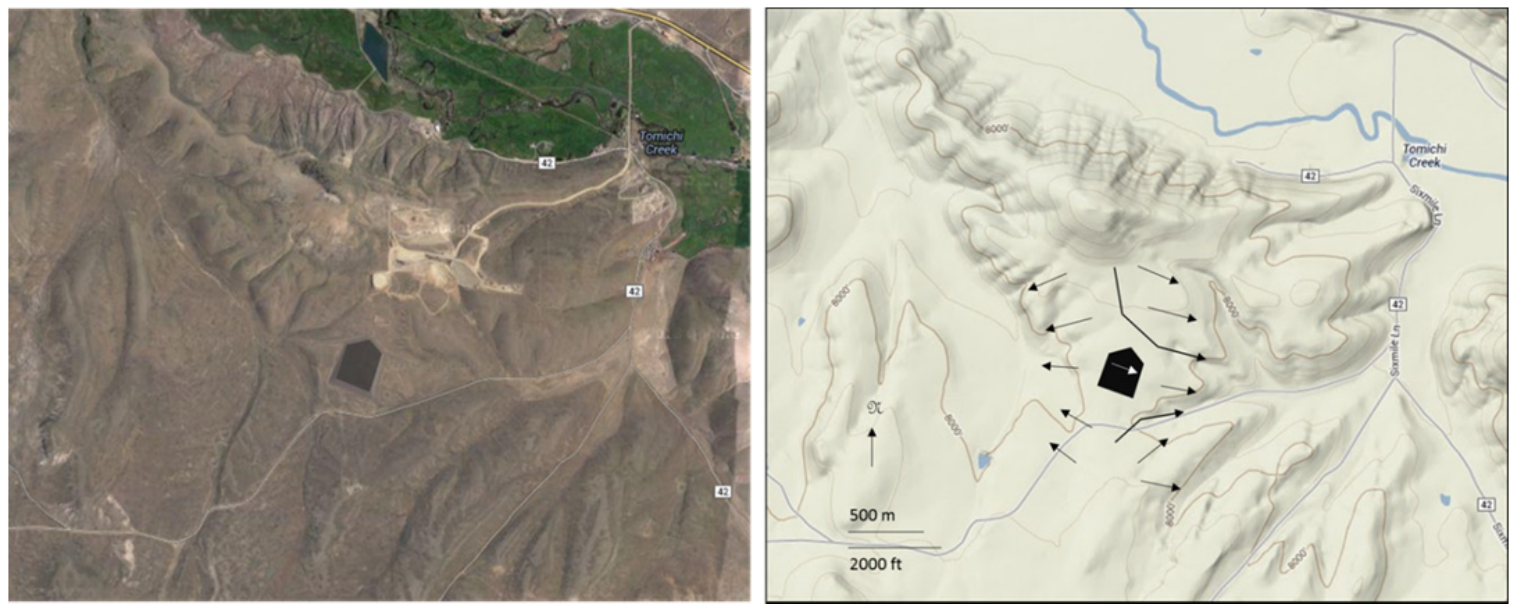

Figure 23. Gunnison Disposal Site: Cell containing stabilized tailings and contaminated materials removed from the Gunnison Processing Site 
Gunnison Processing Site -- The former mill processed approximately 540,000 tons of uranium ore between 1958 and 1962. At the end of operations, radioactive mill tailings, a predominantly sandy material, covered approximately 39 acres at the mill site. Uraniumore processing activities also resulted in contaminated groundwater beneath the site. The State of Colorado acquired ownership of the Gunnison processing site in 1990; ownership of the site has since been transferred to Gunnison County. Uranium is the primary constituent of concern in groundwater - uranium concentrations exceed the EPA groundwater standard in a plume that extends about 4,000 feet downgradient from the site. The compliance strategy for groundwater remediation at the Gunnison processing site is natural flushing in conjunction with continued monitoring and institutional controls to prevent harmful exposure. As discussed above, the processing site is currently being transitioned to beneficial reuse. The review team supports the DOE-LM strategy at the Gunnison Processing Site and their careful and active efforts to manage the site to help assure protection of human health and the environment.

The Gunnison Processing Site is a reasonable exemplar of a LM "flushing site." As with Tuba City, increased focus on the hydrologic framework may be particularly important for understanding and managing the Gunnison Processing Site into the future. The processing site area is bracketed by two nearby streams, the Tomichi Creek and the Gunnison River; these stream waters interact with the shallow groundwater. Much of the land between the former processing site and the creek/river is relatively flat and characterized by moist conditions. Groundwater is relatively shallow in this downgradient area, dynamically interacting with the streams and vegetation. Importantly, there is a gravel mining operation in the vicinity that significantly impacts the groundwater, especially when dewatering by pumping large volumes of groundwater from the large excavations is needed (see Figure 17, inset). The net result of these multiple and interacting hydrologic boundary conditions is that the uranium plume in the groundwater is relatively limited in extent and appears relatively stable. This apparent stability, however, is partly a function of the balance of the dynamic hydrologic conditions. The mining operation has mineral rights to a large portion of the land between the former processing facility and the bounding creek with plans for expansion and eventual mining of the area currently occupied by livestock grazing. In this setting, hydrologic boundary conditions are particularly important (and not under DOE control). The review team recommends evaluating the monitoring strategy at this site to emphasize hydrologic boundary conditions. Further we recommend developing effective collaboration and agreements with local industries and county to provide opportunities to evaluate future incidental groundwater use scenarios (e.g., dewatering) 
and mitigate potential adverse collateral impacts if they are identified - for example, by strategically sequencing where mining operations are conducted.

\section{Gunnison Disposal Site}

From 1992 to 1995, tailings and other contaminated materials were removed from the Gunnison processing site and local contaminated vicinity properties. Supplemental standards were developed for thorium-230 that was left in place on the processing site. Contaminated materials that were removed from the processing site were transported to and stabilized in a disposal cell located 6 miles east of Gunnison. The U.S. Department of Energy (DOE) completed construction of the disposal cell in 1995. The disposal cell occupies 29 acres of a 115-acre site that was transferred from the Bureau of Land Management to DOE. Based on the hydrologic framework, the disposal site should provide a high level of protection. As shown by the annotation arrows in figure 19, surface water is shed in all direction away from the disposal cell. The vadose zone is relatively thick beneath the disposal cell there is minimal driving force to move contaminants to the groundwater. Thus, the disposal cell is well located and should provide reasonably robust protection of the groundwater.

\section{$\underline{\text { A Thought Experiment for Mill Tailings }}$}

As described above, the Gunnison Disposal site is well-located and protective of the groundwater and surrounding environment. At the few LM sites with tailings cells closer to communities or closer to the groundwater, there are a range of low cost engineering options that might enhance the performance of the standard tailings cell designs. As a single example (thought, experiment), barometric pumping of a large capped cell has the potential to passively mitigate uncontrolled releases of radon and to passively maintain soil gas at a low relative humidity (keeping the tailings "dry" and further minimizing the potential for transport of contamination to the groundwater). Figure 24 shows: a) standard tailings cell which relies on isolation and shielding and b) tailings cell that has been augmented with barometric pumping to control gas movement. In the latter case, the cap isolates the tailings and provides a small driving force for gas movement and barometric pressure rises and falls. In this case, the tailings are vented during periods of low barometric pressure and radon emissions are passively directed to the vent wells where they can be captured on activated carbon - the radon and daughters would then decay rapidly in this controlled location. The episodic venting of the cell would provide a net movement of air from the surrounding soil into the cell and limit the potential for releases to the soil and atmosphere. Similarly, the barometric check valve can be configured to allow fresh air to enter the tailings cell during high barometric pressure periods. This provides an opportunity to add relatively low humidity air to the system so that engineers can passively "dry" the tailings and limit the potential for moisture release to the subsurface and provide and additional layer of defense. As noted above, this concept is not applicable to Gunnison and other LM sites that are providing a high level of protection with the standard design, but it might be applicable to sites where local exposures are a concern such as the Homestake Site (which may be slated for future transfer to LM) and other similar tailings sites. 


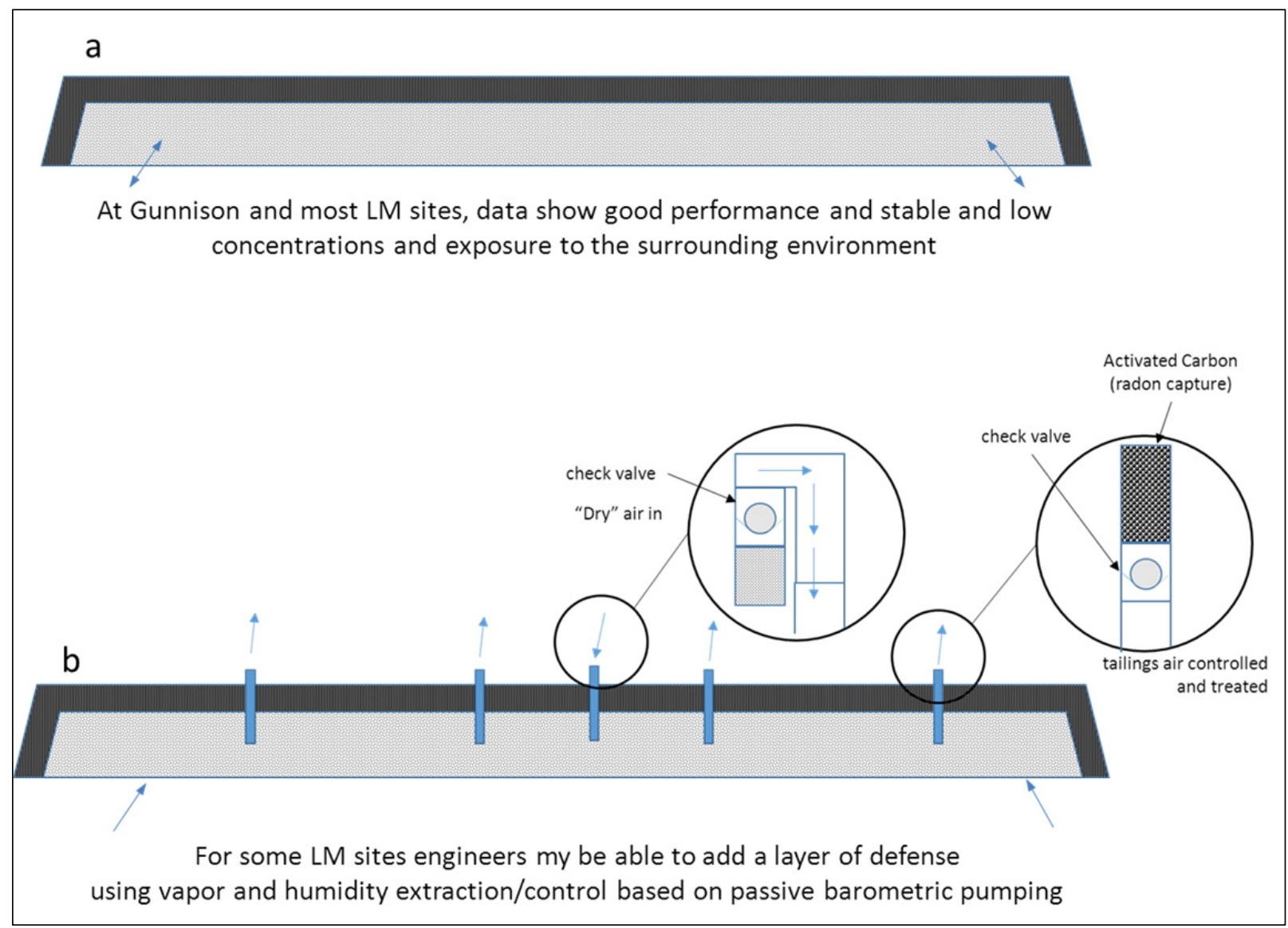

Figure 24. Example Concept - Passive Barometric pumping for control of vapor moisture in a hypothetical tailings cell; a) standard cell and b) barometric pumping augmented cell 


\subsection{Recommendations and Conclusions}

The TAT found the efforts of DOE-LM and their contractors to be of high quality, consistent with a high performing organization. Nonetheless, we urge incorporation of the recommended applied science frameworks into the paradigm moving forward. In particular, the hydrologic and geochemical frameworks appear to be particularly relevant to the large number of LM sites in the western "arid" portion of the United States. At Tuba City, this framework approach has a high potential to be transformational providing the technical bases: to document protection of human health and the environment, for safe shutdown of an "ineffective" p\&t system, and to support sustainable and beneficial future use. If successful, equal or improved protection of the environment could be achieved with a significant potential cost savings (e.g., "tens of millions of dollars"). LM has a strong administrative, management and technical staff and contractors that has demonstrated skill in managing their complex portfolio of sites and that is fully capable of incorporating our recommendations throughout the program. Based on the case study sites addressed in our project, we believe that supplementing the existing LM paradigm with applied science frameworks is viable and would be beneficial to many of LM sites with groundwater contamination. 


\section{References Cited}

Alonzo-Zarza, A.M. and V.P. Wright, 2010. Calcretes. Developments in Sedimentology, 61: 225-267.

Arakel, A.V. and D. McConchie, 1982. Classification and Genesis of Calcrete and Gypsite Lithofacies in Paleodrainage systems of Inland Australia and their relationship to Carnotite Mineralization, Journal of Sedimentary Petrology, 52:1149-1170.

Arey, S.J., J.C. Seaman, and P.M. Bertsch, 1999. Immobilization of uranium in contaminated sediments by hydroxyapatite addition. Environmental Science \& Technology, 33: 337-342.

Carlisle, D., 1980. Possible Variations on the Calcrete-Gypcrete Uranium Model. Report No. GJBX-53/80. U.S. Department of Energy Office of Scientific and Technical Information, Oak Ridge TN (www.osti.gov).

Carlisle, D., 1978. The Distribution of Calcretes and Gypcretes in Southwestern United States and their Uranium Favorability: Based on a Study of Deposits in Western Australia and Southwest Africa (Namibia). Report No. GJBX-29/78. U.S. Department of Energy Office of Scientific and Technical Information, Oak Ridge TN (www.osti.gov).

Chenowith, W.L., 1986. The Orphan Lode Mine, Grand Canyon, Arizona: A Case History of a Mineralized, Collapse-Breccia Pipe. U.S. Geological Survey, Open-File Report 86-510.

Chenowith, W.L., 1993. Geology and Production History of the Uranium Ore Deposits in the Cameron Area, Coconino County, Arizona. Arizona Geological Survey, Contributed Report 93-B.

Curti, E., 1999. Coprecipitation of radionuclides with calcite: estimation of partition coefficients based on a review of laboratory investigations and geochemical data, Applied Geochemistry, 14: 433-445.

Bethke, C.M.and S. Yeakel. 2012. The Geochemist's Workbench ${ }^{\circledR}($ geochemical modeling software), Release 8.0 Reference Manual, University of Illinois.

Denham, M. and K.M. Vangelas, 2009. Biogeochemical gradients as a framework for understanding waste site evolution, Remediation, 19: 5-17.

DOE, 2003. Field Performance of a Slimline Turbomist Evaporator under Southeastern U. S. Climate Conditions, WSRC-RP-2003-00429, U.S. Department of Energy Office of Scientific and Technical Information, Oak Ridge TN.

EPA, 1997. Abandoned Uranium Mines and the Navajo Nation: Navajo Nation AUM Screening Assessment Report and Atlas with Geospatial Data. U.S. Environmental Protection Agency Region 9, San Francisco CA. Data DVDs available from EPA Region 9, reports available at:

http://yosemite.epa.gov/r9/sfund/r9sfdocw.nsf/3dc283e6c5d6056f88257426007417a2/8ed3f74d2f55b8458882573f400787a8e . 
Finch, R.J. and R.C. Ewing, 1992. The corrosion of uraninite under oxidizing conditions, Journal of Nuclear Materials, 190: 133-156.

Flach, G.P. 2002. Evaluation of Evaporation Technologies for Treating Contaminated Groundwater, WSRC-TR-2002-00432, U.S. Department of Energy Office of Scientific and Technical Information, Oak Ridge TN.

Fogg, G.E. and R.K. Senger, 1985. Automatic generation of flow nets with conventional groundwater modeling algorithms. Ground Water, 23:3, pp 336-344.

Frondel, C., 1958. Systematic Mineralogy of Uranium and Thorium, United States Department of Interior - Geological Survey, Bulletin 1064.

Havens, R. and E.C. Dean, 1967. Chemical Stabilization of the Uranium Mill Tailings at Tuba City, AZ. (Report of Investigation 7288) US Department of the Interior, Washington DC.

Health Canada, 2000. Canadian Guidelines for the Management of Naturally Occurring Radioactive Material, Canadian NORM working group of the Federal Provincial Territorial Radiation Protection Committee, Health Canada, Toronto Canada.

ITRC (Interstate Technology \& Regulatory Council). 2010. Use and Measurement of Mass Flux and Mass Discharge. MASSFLUX-1. Washington, D.C.: Interstate Technology \& Regulatory Council, Integrated DNAPL Site Strategy Team. www.itrcweb.org.

Jeanjean, J., J.C. Rouchaud, L. Tran, and M. Fedoroff, 1995. Sorption of uranium and other heavy metals on hydroxyapatite, Journal of Radioanalytical and Nuclear Chemistry, Letters, 201; 529-539.

Jutras, P., J. Utting and J. McLeod, 2007. Link between long-lasting evaporitic basins and the development of thick and massive phreatic calcrete hardpans in the Mississippian Windsor and Percé groups of eastern Canada, Sedimentary Geology, 201:75-92.

Knox, A.S., R.L. Brigmon, D.I. Kaplan, and M.H. Paller, 2008. Interactions among phosphate amendments, microbes and uranium mobility in contaminated sediments, Science of the Total Environment, 395: 63-71.

Landa, E.R., 2004. Uranium mill tailings: nuclear waste and natural laboratory for geochemical and radioecological investigations, Journal of Environmental Radioactivity, 77: $1-27$.

Looney, B.B and R.W. Falta, eds., 2000. Vadose Zone Science and Technology Solutions. Battelle Press, Columbus OH. See for example pp 11-13 \& pp 50-57.

Mann A.W. and R.C. Horwitz, 1979. Groundwater calcrete deposits in Australia: some observations from Western Australia, Journal of the Geological Society of Australia, 26:293-303. 
Morrison, S. 1996, Groundwater Geochemistry of the Tuba City Site, GWTUB13.1.

Newell, C.J., H.S. Rifai, J.T. Wilson, J.A. Connor, J. A. Aziz and M.P. Suarez. 2002. Ground Water Issue: Calculation and Use of First-Order Rate Constants for Monitored Natural Attenuation Studies, EPA/540/S-02/500, US Environmental Protection Agency National Risk Management Research Laboratory, Cincinnati $\mathrm{OH}$.

NNEPA, 2011. Highway 160 Project Completion Report, Project G7644, Navajo Nation Environmental Protection Agency, Window Rock AZ.

Peterson, J.A., D.P. Cox, and F. Gray, 1985. Mineral Resource Assessment of the Ajo and Laveville $1^{\circ}$ by $2^{\circ}$ Quadrangles, Arizona. U.S. Geological Survey, Reston VA, supplement to map MF-1834-B.

Phillips, J.D., J.S. Duval, and R.A. Ambrosiak, 1993. National Geophysical Data Grids: Gamma-Ray, Magnetic, and Topographic Data for the Conterminous United States, U.S. Geological Survey Digital Data Series DDS-9.

Purvis, K. and V. P. Wright, 1991. Calcretes related to phreatophytic vegetation from the Middle Triassic Otter Sandstone of South West England, Sedimentology, 38:539-551.

Raicevic, S., J.V. Wright, V. Veljkovic, J.L. Conca, 2006. Theoretical stability assessment of uranyl phosphates and apatites: Selection of amendments for in situ remediation of uranium, Science of the Total Environment, 355: 13-24.

Reeder, R.J., M. Nugent, C.D. Tait, D.E. Morris, S.M. Heald, K.M. Beck, W.P. Hess, and A. Lanzirotti, 2001. Coprecipitation of uranium (VI) with calcite: XAFS, micro-XAS, and luminescence characterization, Geochimica et Cosmochimica Acta, 65: 3491-3503.

Spotl, C. and V.P. Wright, 1992. Groundwater dolocretes from the Upper Triassic of the Paris Basin, France: a case study of an arid, continental diagenetic facies, Sedimentology, 39:1119-1 136

Shi, Z., C. Liu, J.M. Zachara, Z. Wang, and B. Deng, 2009. Inhibition effect of secondary phosphate mineral precipitation on uranium release from contaminated sediments, Environmental Science \& Technology, 43: 8344-8349.

Tyler, S.W., J.F. Munoz, and W.W. Wood, 2006. The Response of Playa and Sabkha Hydraulics and Mineralogy to Climate Forcing, Ground Water, 44:329-338.

Tokunaga, T.K., Y. Kim, and J. Wan, 2009. Potential remediation approach for uraniumcontaminated groundwaters through potassium uranyl vanadate precipitation, Environmental Science \& Technology, 43: 5467-54-71.

Wan, J., W. Dong, T.K. Tokunaga, 2011. Method to attenuate U(VI) mobility in acidic waste plumes using humic acids, Environmental Science \& Technology, 45: 2331-2337. 


\section{Appendix A}

\section{Independent Technical Review Team STATEMENT OF WORK}

\section{Independent Review of DOE’s UMTRCA Groundwater Program}

\section{Scope Statement:}

Perform an independent review of the U.S. Department of Energy (DOE) Legacy Management (LM) Uranium Mill Tailings Radiation Control Act (UMTRCA) Groundwater Program at three selected sites. The reviewer will be provided a select set of questions to answer which focus on assessing the program's effectiveness in protecting human health and the environment at each site. A review of site-specific documents provided (i.e., plans and reports) will be performed in order to obtain a sufficient understanding of the site that is necessary to make a technically valid assessment. The reviewer will submit a write-up that provides site-specific answers for each question, along with an overall assessment of the program's effectiveness at each site (in the form of a conclusion that includes recommendations regarding the implementation of the groundwater program).

\section{Selected Sites:}

The following three specific UMTRCA disposal sites have been selected:

- Tuba City, Arizona, UMTRCA Title I Disposal Site (an active groundwater remediation site and cell performance site),

- Gunnison, Colorado, UMTRCA Title I Processing Site (a natural flushing site),

\section{Specific Questions to be Answered:}

The following questions were developed to provide a framework for conducting and presenting the findings of this review:

1. Overall, has the long-term surveillance (LTSM) program demonstrated that the actions taken by DOE are protective of human health and the environment at the site?

a. Have there been any human health and the environment impacts as a result of the LTSM project execution?

i. If so, have appropriate mitigative measures been taken?

b. Is there a programmatic plan for LTSM?

i. Is there sufficient evidence that a consistent approach is being followed?

ii. Is a formalized monitoring plan used to execute LTSM at the site? 
iii. Does the documentation indicate a quality assurance (QA) plan is in place to handle sampling and analysis validation?

iv. Is a rational statistical approach to monitoring being followed?

v. Are decision rules clearly stated in the groundwater compliance action plan (GCAP) so LM will know when compliance is achieved or an action is required?

c. Is there sufficient documentation provided to demonstrate the conclusion that the LTSM program is or is not protective?

i. Have sufficient data been collected to support such an assertion?

ii. Have statistical analyses been used to support this conclusion?

iii. Has sufficient time passed to allow an evaluation of this question?

d. Is an indication of remediation progress given for the site?

2. Does the documentation provided indicate that there is a good understanding of the groundwater flow and transport system at the site?

a. Is an adequate conceptual model provided?

b. Does the monitoring network apparently define the contaminant plume present at each site?

\section{Documents Provided:}

The following is a list of the types of documents that will be provided for review (if available) for developing a sufficient understanding of each site so that a technically valid assessment can be made:

- Reclamation Plans,

- Remedial Action Plans,

- Completion Reports,

- Site Observational Work Plans,

- Alternate Concentration Limit Applications,

- Groundwater Fate and Transport Modeling Reports

- Long-Term Surveillance Plans,

- Ground Water Compliance Action Plans,

- Sampling and Analysis Plans

- Data Validation Reports,

- Verification Monitoring Reports,

- Annual Site Inspection and Monitoring Reports,

- Environmental Procedures Manuals,

- Quality Assurance Manuals. 


\title{
Appendix B.
}

\section{Independent Technical Review Team Team Member Biographies}

\author{
Miles E. Denham, Savannah River National Laboratory \\ 773-42A, Aiken SC 29808 \\ 803-725-5521 \\ miles.denham@srnl.doe.gov
}

Miles Denham is a research geochemist at the Savannah River National Laboratory (SRNL) studying metal and radionuclide contamination in soil and groundwater. He began his career at SRNL in 1992 following receipt of his Ph.D. from Texas A\&M University. His research focuses on innovative practical methods of remediating metal and radionuclide contaminated sites, as well as developing characterization techniques that facilitate remediation. Specific interests include environmental mineralogy and geochemical heterogeneity in the subsurface.

Dr. Denham has applied his expertise as lead geochemist on successful site closures across the Savannah River Site. In addition, he has served on numerous teams that have provided technical assistance on characterization and remediation at different sites across the Department of Energy (DOE) complex. Currently, Dr. Denham is the technical lead on a national applied research effort on developing the use of natural attenuation and enhanced attenuation remedies for metal and radionuclide contamination of soils and groundwater. The DOE Office of Environmental Management that is funding this effort has also recently funded Dr. Denham to study enhanced attenuation remedies in Chernobyl Exclusion Zone soils. Dr. Denham is author on numerous publications and in 2009 received a research award from the American Association of Petroleum Geologists Division of Environmental Geosciences for his contributions to the field of environmental geosciences.

\section{Carol A. Eddy-Dilek}

773-42A, Aiken SC 29808

803-761-1826

carol.eddy-dilek@srnl.doe.gov

Carol Eddy-Dilek is a Senior Technical Advisor at the Department of Energy Savannah River National Laboratory. For the past 25 years, she worked on a variety of programs focused on development and deployment of innovative approaches and tools for environmental characterization and remediation, specifically, the design and optimization of phased characterization strategies that can be applied to complex and challenging environments. Her efforts resulted in the successful development or deployment of over fifty innovative methods for subsurface access and characterization that have been successfully applied within the DOE complex.

Since 2002, she has been the technical lead for the Department of Energy's Technical Assistance program at the Savannah River National Laboratory that provides technical support to the DOE complex. Since 2006, she has organized more than 25 teams that have visited eleven DOE sites and made recommendations yielding an estimated cost savings of \$100M. From 2002 to 2006, she coordinated technical assistance activities for the DOE Ohio Closure Sites (Fernald, 
Ashtabula and Mound) which provided technical experts to address challenging environmental issues that were encountered during the expedited closure process.

From 1996 to 2001 she initiated and managed a program for the DOE complex program that developed, tested and evaluated more than twenty innovative characterization technologies for the cone penetrometer that resulted in widespread acceptance of direct push methods for site characterization. The program began at SRS and eventually resulted in successful application of innovative approaches and technologies at many federal and commercial sites. From 1999 to 2001 she was the DOE lead for the Interagency DNAPL consortium program the Cape Canaveral, a joint EPA-DoD-DOE program for evaluation of DNAPL characterization and remediation technologies.

\section{Brian B. Looney, Savannah River National Laboratory}

773-42A, Aiken SC 29808

803-725-3692

Brian02.looney@srnl.doe.gov

Dr. Brian Looney is a Senior Advisory Scientist with the Savannah River National Laboratory and an adjunct professor in the Earth and Environmental Science Department at Clemson University. Brian earned a B.S. in Environmental Science from Texas Christian University and a Ph.D. in Environmental Engineering from the University of Minnesota. For the past 29 years, he has developed environmental characterization and remediation technologies for organic contaminants, metals and radionuclides. His work focuses on matching characterization and cleanup technologies to the specific conditions and needs at each site and developing technical approaches for that matching process. Dr. Looney coordinates development and deployment of innovative environmental characterization and clean-up methods at the Savannah River Site, and serves as a technical advisor supporting the DOE Environmental Management Program. He has received numerous awards and has authored and edited many publications including the recent book, Vadose Zone Science and Technology Solutions. Dr. Looney has ten patents for innovations in environmental technology.

\section{Maggie R. Millings, Savannah River National laboratory}

773-42A, Aiken SC 29808

803-725-6230

margaret.millings@srnl.doe.gov

Maggie Millings is a Principal Scientist at the Savannah River National Laboratory with a primary focus on the influence of geology and geochemistry on contaminant transport. She began her career at SRNL in 2001 after receiving a M.S. from University of Georgia. Research projects have included sulfate reduction to remediate coal pile runoff, natural radium in groundwater at SRS, documenting and mapping the ecosystem impacts of an outcropping groundwater plume, humate addition for treatment of copper in surface water, and humate injection for treatment of uranium in groundwater. Ms. Millings currently manages the E-Area vadose zone monitoring system and is PI on an LDRD project investigating remediation of Sr-90 in high calcium waters. 